\title{
Modeling with Mixed Frequency Variables: A Review of Recently Extended Methods in Time Series Econometrics
}

\author{
Naser Khiabani ${ }^{1}$ \\ Fateme Rajabi ${ }^{2}$
}

\author{
Naser.khiabani@atu.ac.ir \\ Fateme.rajabi@atu.ac.ir
}

\begin{abstract}
Recent theoretical econometric studies have focused on mixed frequency data. These studies are of great importance since they emphasize the role of information in economic modeling. In the current Time Series approach, temporal aggregation is often turned to a period of identical alternation; however, such aggregation leads to information loss in higher-frequency data. The mixed frequency studies provide a way to avoid the need for such temporal aggregation. In particular, the main result of this branch of econometric studies is to improve explanatory power, prediction, and efficiency in time series modeling with mixed frequency data. Accordingly, this paper attempts to specify the developments and shortcomings of this new branch of econometrics by reviewing the extant literature.
\end{abstract}

Keywords: Mixed Frequency Data, Temporal Aggregation, Time Series, Efficiency, MIDAS Regression.

JEL Classification: C12, C32.

1. Associate Professor, Faculty of Economics, Allameh Tabataba'i University, Tehran. Iran (Corresponding Author).

2. Ph.D. Student of Economics, Allameh Tabataba'i University, Tehran. Iran. 


\section{مدلسازى با متغيرهاى دوره تناوبى مختلط: مرورى

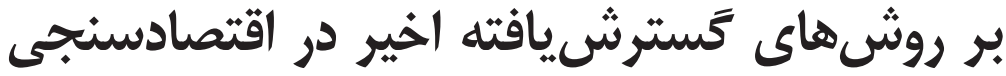

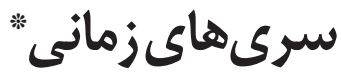

Naser.khiabani@atu.ac.ir

Fateme.rajabi@atu.ac.ir

ناصر خيابانى

دانشيار دانشكده اقتصاد دانشعاه علامه طباطبايى

(نويسنده مسئول).

فاطمه رجبى (نويسن دانشجوى دكترى رشته اقتصاد دانشعاه علامه طباطبايى. نوع مقاله: بزوهشى

קجيده: يزوهش هاى اقتصادسنجى نظرى جديد بر اين واقعيت متمركز هستند كه دوره تناوبى

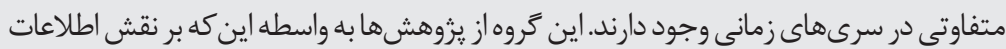

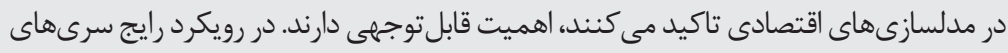

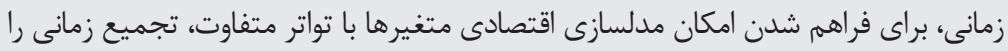

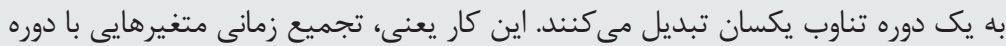

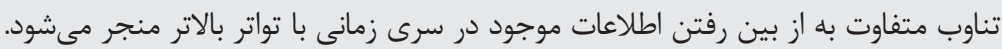

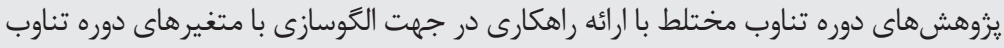

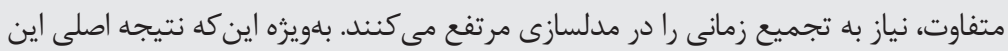

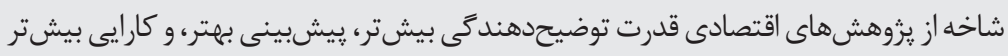

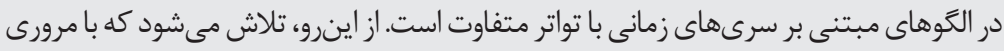

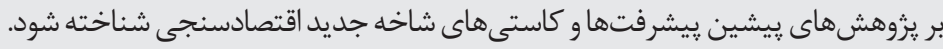

كليدوازهها: دادهاى دوره تناوبى مختلط، تجميع زمانى، سرىهاى زمانى، كارايى، ركرسيون MIDAS.

طبقهبندى C12, C3EL.

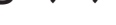

* مقاله مستخرج از رساله دكترى دانشجو به راهنمايى دكتر ناصر خيابانى در دانشكاه علامه طباطبايى است. 


\section{مoloto}

در مدلسازىهاى اقتصادى تلاش مىشود كه با كمك روشهاى اقتصادسنجى و با استفاده از اطلاعات موجود در سرىهاى زمانى اقتصادى، به تحليل وضع موجود و پيشبينى مدى آينده اقتصاد קرداخته شود، تا از اين راه به تصميمَيرى عوامل اقتصادى و سياستخذارى كمك شود. اين در حالى است كه سرىهاى زمانى با دوره تناوبى متفاوت در دسترس هستند. براى مثال، شاخصهاى

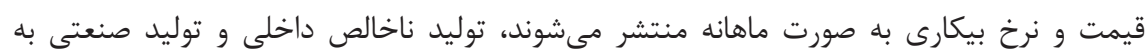
صورت فصلى كزارش مىشوند، دادههاى بازار سهام به صورت روزانه در دسترس است، و نرخ ارز و و قيمت نفت به صورت ساعتى در اختيار است. در جنين شرايطى، براى بررسى يك يديده اقتصادى، بردارى از متغيرهايى با دوره تناوبى متفاوت وجود دارد. به همين دليل، يزوهشگران اقتصادسنجى نظرى بايد رويكرد مناسبى براى مواجهه با اين واقعيت ـ دوره تناوبى متفاوت متغيرها ـ ارائه كنند.

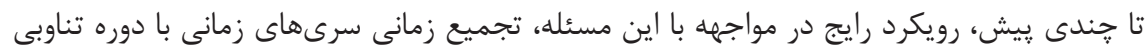

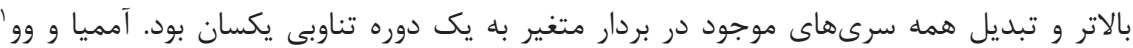

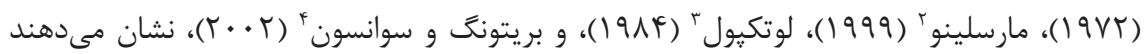

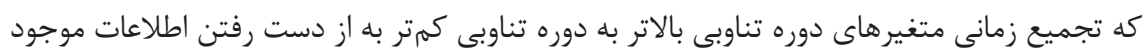

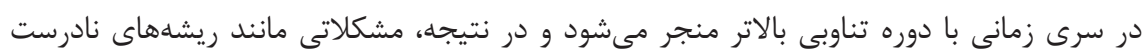

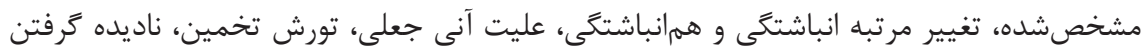

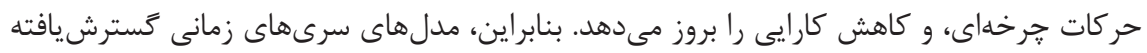

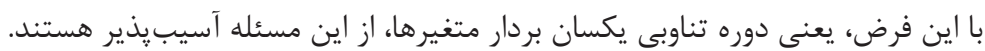

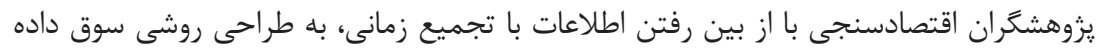

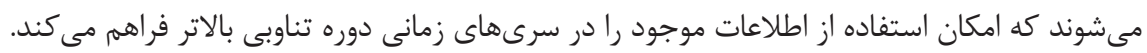

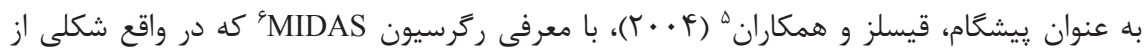
ركرسيون با وقفههاى توزيعى است، امكان اجراى ركرسيون را با متغيرهاى دوره تناوب مختلط فراهم

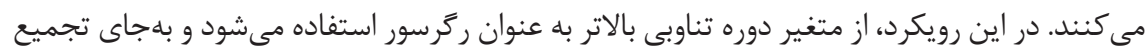

1. Amemiya \& $\mathrm{Wu}$

2. Marcellino

3. Lütkepohl

4. Breitung \& Swanson

5. Ghysels et al.

6. Mixed Data Sampling (MIDAS) Regression 


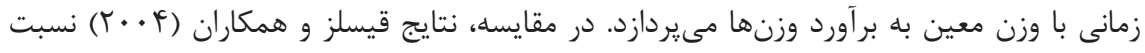

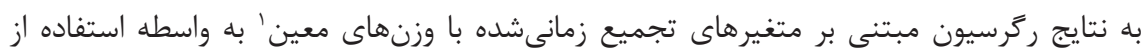

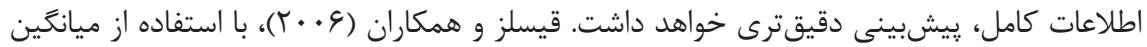

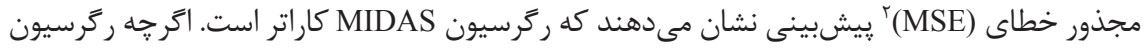
MIDAS

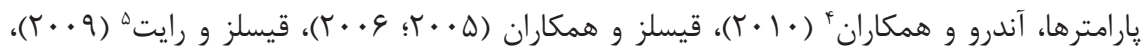

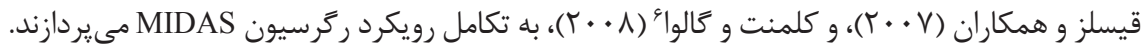

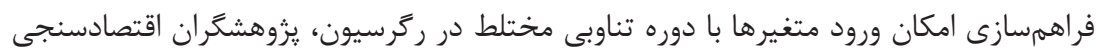
را به سمت گسترش مدلسازىهاى سنجى بر پايه متغيرهايى با دوره تناوبى مختلط هدايت مى كند. از اينرو، طيف وسيعى از يزوهشها بر يايه رگرسيونهاى MIDAS به تكامل روشهاى اقتصادسنجى

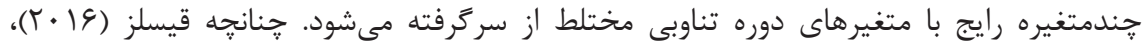

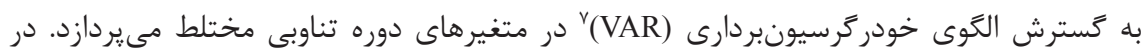

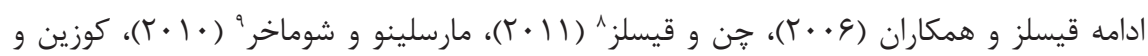

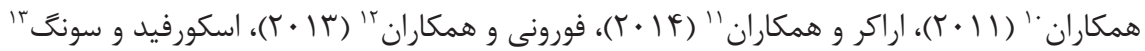

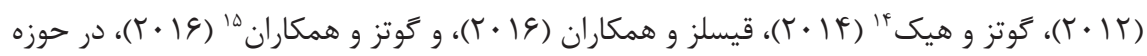

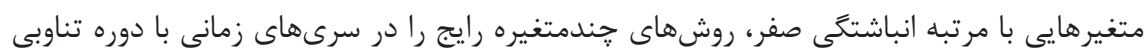
يكسان گسترش مى دهند.

2. Mean Squared Errors 1. - ويكرد رايج

3. Parameter Proliferation

4. Andreou et al.

5. Ghysels \& Wright

6. Clements \& Galvão

7. Vector Autoregressive Model

8. Chen \& Ghysels

9. Marcellino \& Schumacher

10. Kuzin et al.

11. Eraker et al.

12. Foroni et al.

13. Schorfheide \& Song

14. Götz \& Hecq

15. Götz et al. 
در حوزه سرىهاى زمانى انباشته از مرتبه يكم نيز يزوهشكران اقتصادسنجى با تاكيد بر اهميت

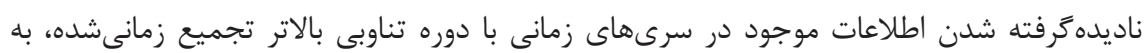

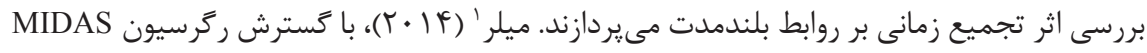

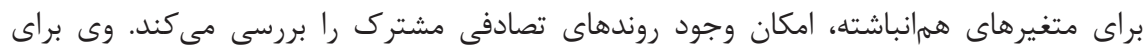

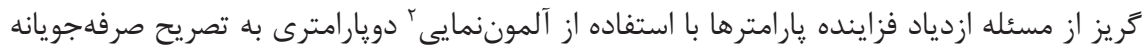
CO-MIDAS متغيرهاى دوره تناوبى مختلط MF-ADL براى سرىهاى زمانى انباشته از مرتبه يكى با دوره تناوبى بـى متفاوت تعميم مى دهند. يزوهشها در شاخه سرىهاى زمانى انباشته از مرتبه يكمم به روشهاى مهاى

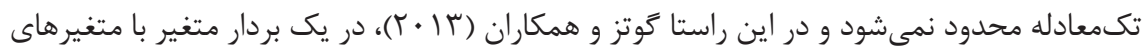

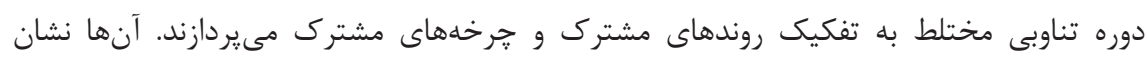

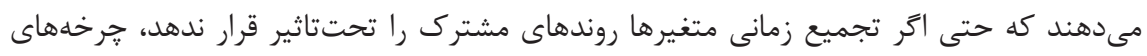

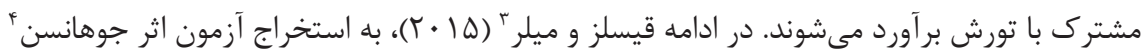

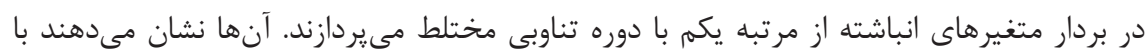
وجود آنكه تجميع زمانى به تورش در تخمين بردار همانباشتكى منجر نمى شود، اما تحريف اندازه

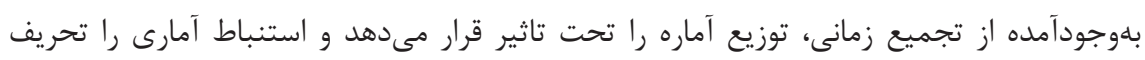

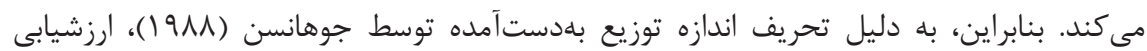

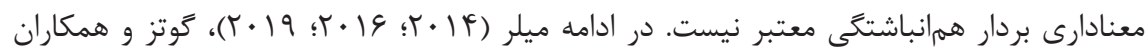

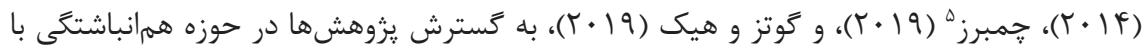
متغيرهاى دوره تناوبى مختلط مىيردازند.

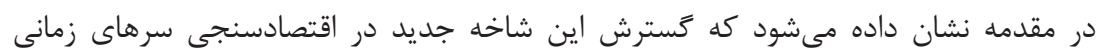

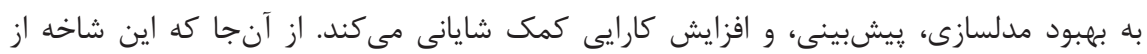

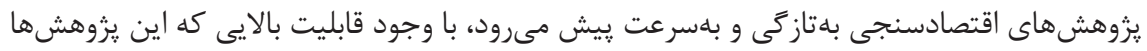

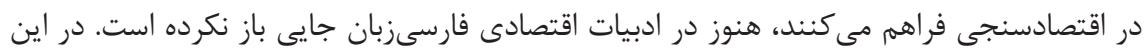

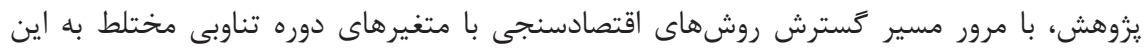

1. Miller

2. Exponential Almon

3. Ghysels \& Miller

4. Trace Test Johansen

5. Chambers 
شكاف ياسخ مى دهيم. علاوه بر اين، يزوهش حاضر به خواننده كمك مى كند كه با دنبال كردن سير گَسترش مدلهاى دوره تناوب مختلط و با شناخت قابليتها و معايب هر الكَ، روش مناسبى براى مدلسازى اقتصادى انتخاب كند. در ادامه، ويزگى هاى اصلى هر يك از شاخهها توصيف مىشود، مزايا و معايب آنها مطرح مىشود،

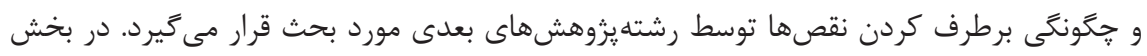

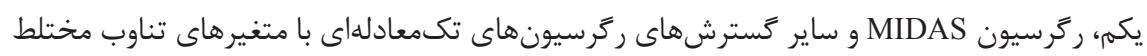

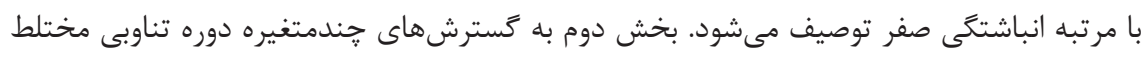

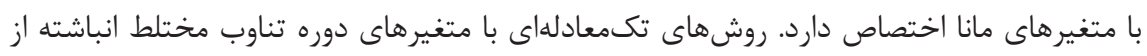

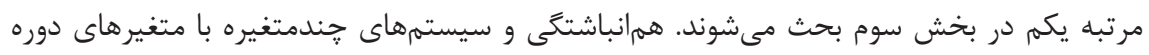

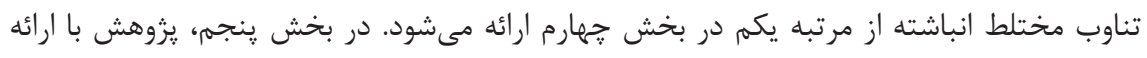
بحث و نتيجهَ كيرى پايان مى يذيرد.

سرىهاى زمانى اقتصادى با دوره تناوبى متفاوتى منتشر مىشوند. براى مثال، توليد ناخالص

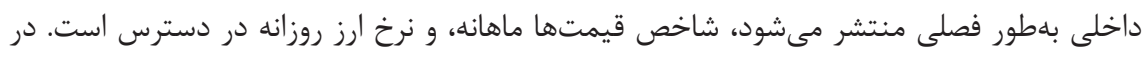
مدلسازىهاى اقتصادى، رويكرد رايج در مواجها با اين يديده، تجميع زمانى متغير با دوره تناوبى مانى

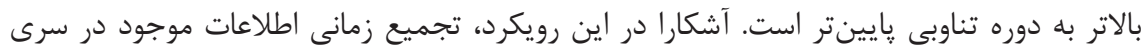
زمانى با دوره تناوبى بالاتر ناديده كرفته مىشود و به همين دليل، تورش در تخمين و تحريف توزيع

ا. نياز به يادآورى است كه ترتيب يزوهشها در سير مرورى به لحاظ كسترش الكَوهاست. اكرجه ممكن است

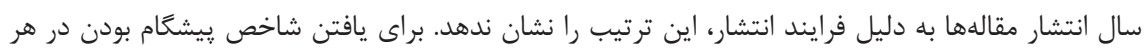

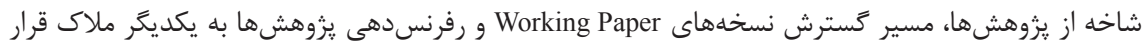

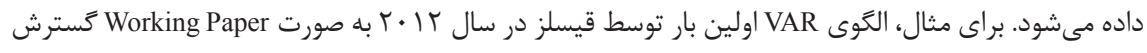

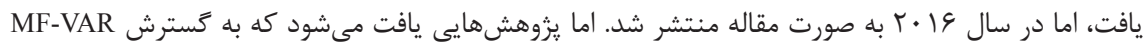

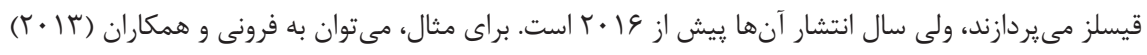


را بهوجود مى آورد. نكرانى اثرهاى از بين رفتن اطلاعات به دليل تجميع زمانى را مىتوان در آمميا

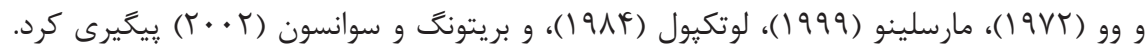
آمميا و وو (YVT (1)، در يك مدل VAR به بررسى اثر تجميع زمانى مىيردازند و با استفاده از معيار

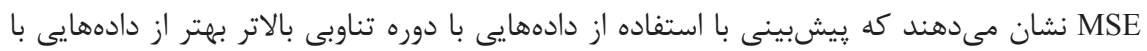
دوره تناوبى پايينتر است.

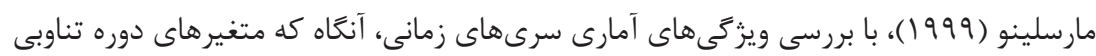

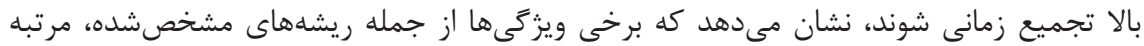

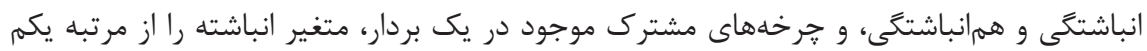

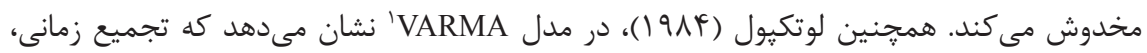

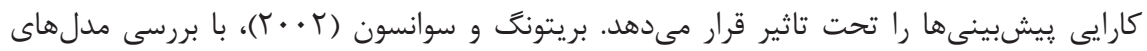

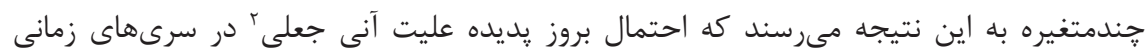

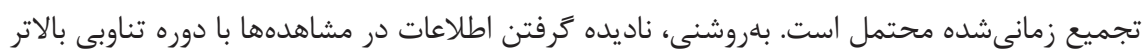

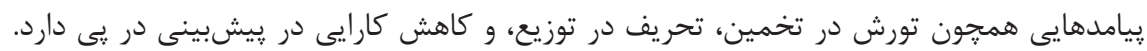
اين موضوع الزام بازنكرى در روشهاى سرىهاى زمانى را با يِشفرض دوره دوره تناوبى يكسان آشكار

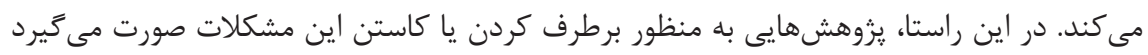

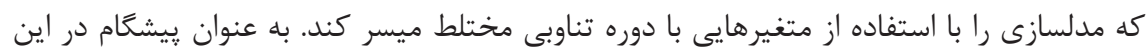

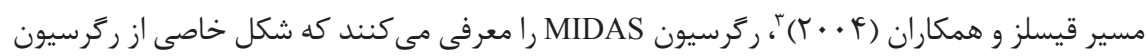
با وقفههاى توزيعى است، بهكونهاى كه امكان استفاده از متغيرهايى با دوره تناوبى مختلط را ايجاد

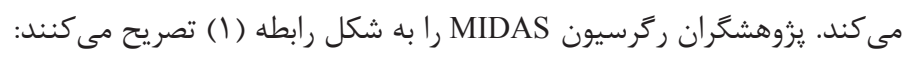

$y_{t}=\beta_{0}+B\left(L^{\frac{1}{m}}\right) x_{t}^{(m)}+\varepsilon_{t}^{(m)}$

كه $y_{t}$ ضر يب جندجملهاى وقفه به شكل

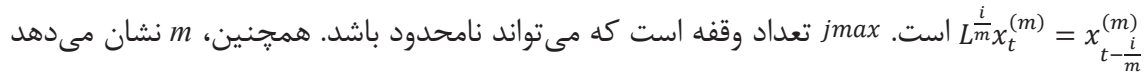

1. Vector Autoregressive Moving Average

2. Spurious Instantaneous Causality

3. The MIDAS Touch: Mixed Data Sampling Regression 
كه هر متغير تناوب بالا در طول هر يك دوره از تناوب يايين m بار مشاهده مىشود و در نماد نشاندهنده 1$\rangle$ - $i \in\langle 0, m$ امين بار مشاهده متغير تناوب بالا درون دوره t ام است.' در واقع، ايده

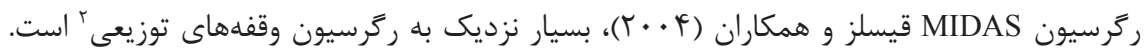
ملاحظه مىشود كه وقفههاى متغير دوره تناوبى بالا، كه در طول يك دوره تناوب يايين مشاهده

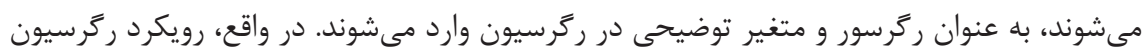
MIDAS

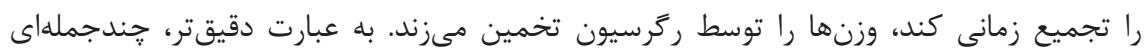
بودن وقفه

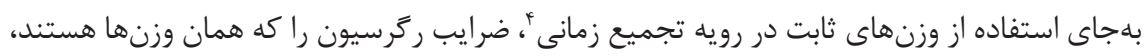

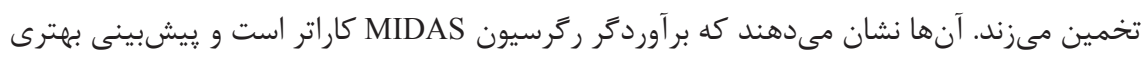

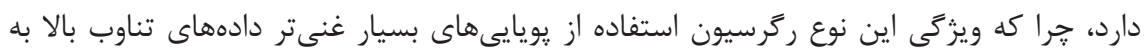

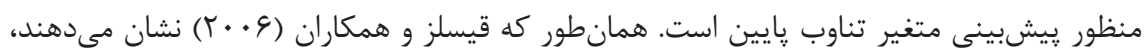

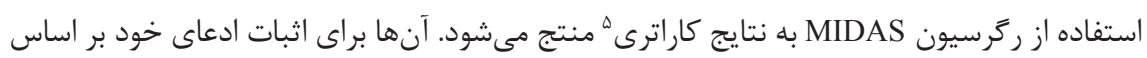

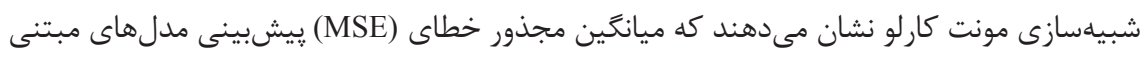

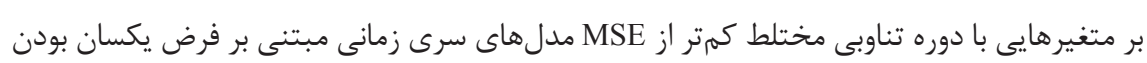

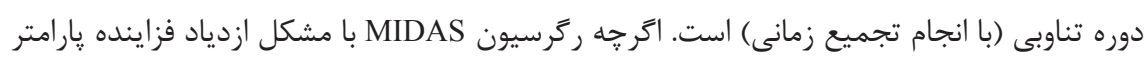
مواجه است. براى مثال، وقتى يك متغير ماهانه در كنار يك متغير سالانه ركرسيون شود، بهجاى رمانى

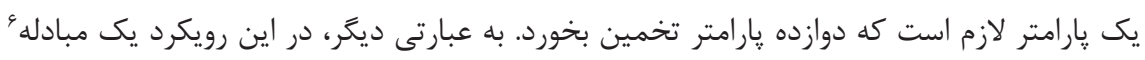

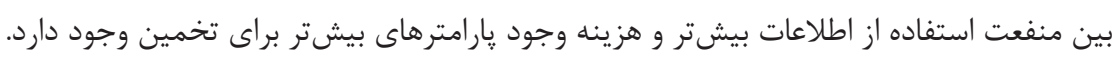

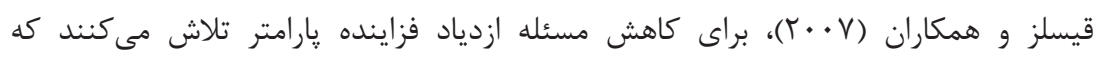
ساختارهاى وقفه مختلفى براى هارامتريزه كردن صرفهجويانه ' ركرسيون ارائه دهند. در اين راستا

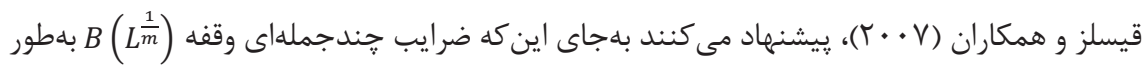

ا. براى مثال، وقتى متغير دوره تناوبى پايين فصلى و متغير دوره تناوبى بالا ماهانه است است.

2. Distributed Lag of Regressors

3. Temporal Aggregation Scheme

5. Efficient f. براى مثال، متوسط ساده كرفتن كه وزنهاى ثابت را لحاظ مى كند.

6. Trade-Off

7. Parameterize Parsimoniously 
كامل در ركرسيون تخمين زده شود، از تصريحهاى متفاوتى براى اين خندجملهاى استفاده شود كه

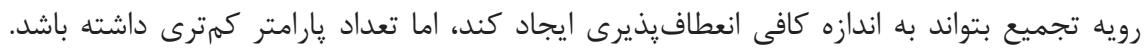
يعنى بلهاى تخمين وزنها در جندجملهاى

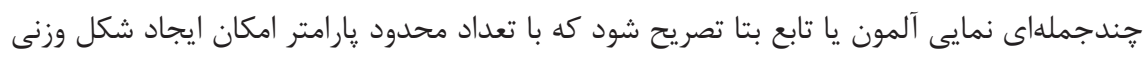

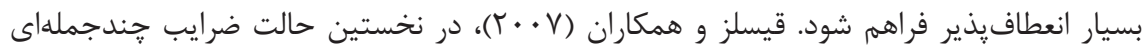

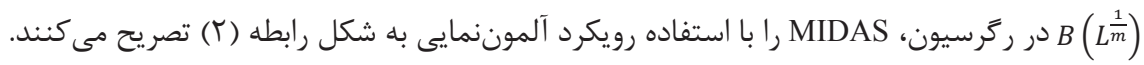

$B(k ; \theta)=\frac{e^{\theta_{1} k+\cdots+\theta_{q} k^{q}}}{\sum_{k=1}^{K} e^{\theta_{1} k+\cdots+\theta_{q} k^{q}}}$

كه بردار $\theta$ شامل $q$ يارامتر است. اين فرم تابع بهطور كامل انعطاف يذير است و مىتواند با تعداد $q$ و

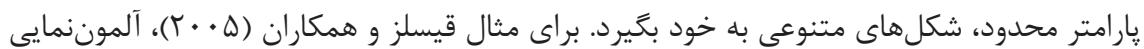

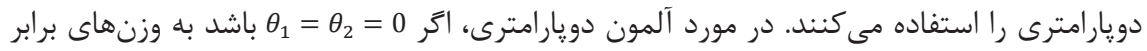
و رويه تجميع زمانى متوسط گيرى ساده مىرسيه. در واقع، ركرسيون سادهاى كه تاكنون با تجميع زمانى، همه متغيرها را به يك دوره تناوبى مشترك تبديل ميى كرد، وقتى مقدار تمام يارامترها صفر در

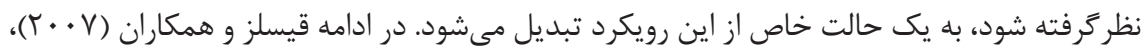

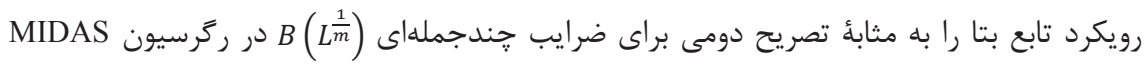
معرفى مى كنند. به شكل رابطه (ب):

$\mathrm{B}\left(k ; \theta_{1}, \theta_{2}\right)=\frac{\mathfrak{f}\left(\frac{k}{K^{\prime}}, \theta_{1} ; \theta_{2}\right)}{\sum_{k=1}^{K} f\left(\frac{k}{K^{\prime}}, \theta_{1} ; \theta_{2}\right)}$

كه انعطافِذير است و مىتواند با تغيير تنها دو پارامتر اشكال كاملاً متنوعى ايجاد كند. در مورد تابع بتا نيز مىتوان با 1 ب 1 به وزنهاى برابر و رويه تجميع زمانى متوسط در رويكرد اوليه ركرسيون MIDAS وقفههاى توزيعى واردشده در ركرسيون محدود نيستند و تعداد

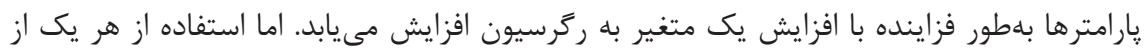

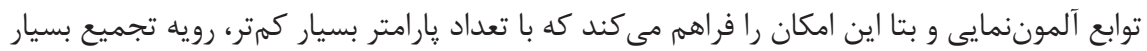
منعطفى ايجاد كرد و به يك راهحل صرفهجويانه در يارامتر براى مشكل ازدياد فزاينده پارامتر در

$$
\text { رَرسيون MIDAS رسيد. }
$$




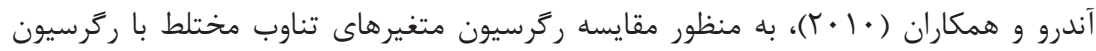
سنتى'، ركرسيون با متغيرهاى تناوب مختلط را به دوجمله تجزيه مي كنند. يك جمله خطى كه همان رگرسيون سنتى با وزنهاى مساوى است، به علاوه يك جمله غيرخطى كه شامل تفاوت وزنهاى فرايند دوره تناوبى بالا با وزنهاى مساوى است. به عبارتى آندرو و همكاران (• • • (Y)، تعبير جديدى براى رگرسيون MIDAS ارائه مى كنند و جندجملهاى وقفههاى توزيعى را نوعى تجميع وزنى در درى

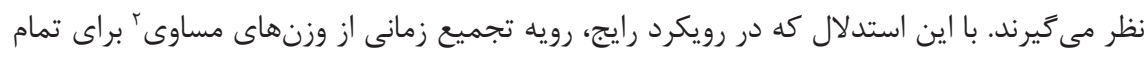

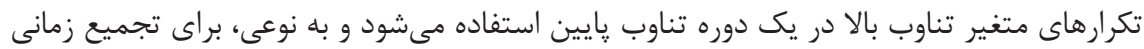

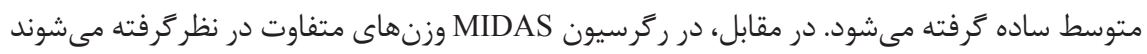

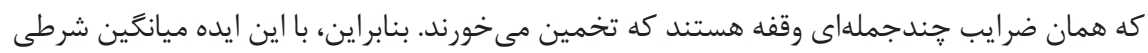
ركرسيون MIDAS را به مجموع دوجمله تجزيه مىكنند كه شامل يك جمله تجميعشده مبتنى بر وزنهاى مساوى و يك جمله غيرخطى است. اين نكاه جديد به رگرسيون MIDAS ارتباطى بين رويكرد ركرسيون سنتى با متغيرهاى دوره تناوبى يكسان و رويكرد جديد - يعنى دوره تناوبى مختلط

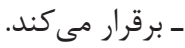
همانطور كه اشاره شد، مشكل عمده رگرسيون MIDAS مسئله ازدياد فزاينده يارامتر است. به

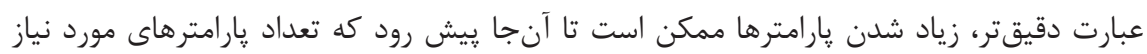
براى تخمين بيشتر از مشاهدهها باشد و در عمل امكان تخمين وجود نداشته باشد. آندرو و همكاران (• (†)، براى مواجه با مشكل يادشده، با اين استدلال كه تجميع زمانى با وزنهاى يكسان به تمام مشاهدههايى كه در تجميع زمانى بكار مىروند، يك وزن مى دهند، درحالى كه مشاهدههاى دورتر

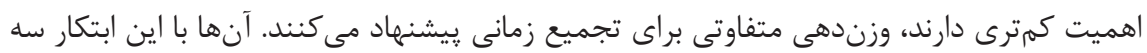

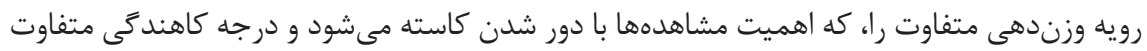
دارند، در كنار وزندهى مساوى يا همان متوسط ساده يیشنهاد مى دهند. بلهطورى كه در هر يك ميك از رويههاى وزندهى، با همان ايده قيسلز و همكاران (V. . .Y)، وزنها با استفاده تابع جندجملهاى وقفهنمايى به يكديكر مرتبط مىشوند و درون ركرسيون تخمين مى خورند. در ادامه، آنان به ارائه تخمين حداقل مربعات غيرخطى MIDAS و بررسى خواص مجانبى برآوردگرها مى يردازند. نتايج

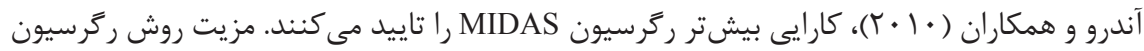


MIDAS متغيرهاى دوره تناوب بالاتر فراهم مى كند و همجنين براى مورد ركرسيون غيرخطى و جندمتغيره

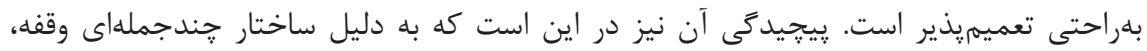

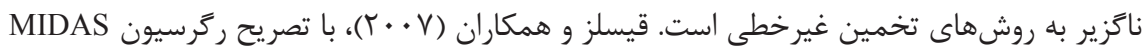

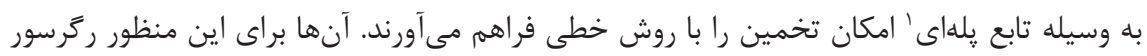
إ به صورت جمعهاى جزئى r $X_{t}(K, m) \equiv \sum_{j=1}^{K} x_{t-\frac{j}{m}}^{(m)}$

$$
\text { ركريون MIDAS عبارت است از: }
$$

$y_{t}=\beta_{0}+\sum_{i=1}^{M} \beta_{i} X_{t}\left(K_{i}, m\right)+\varepsilon_{t}$

با $M$ رَرسور קلهاى كه

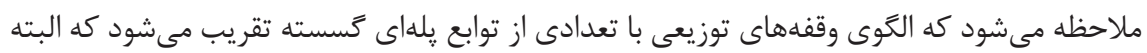

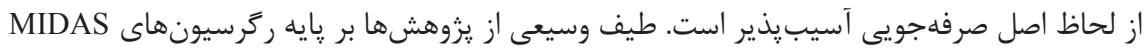

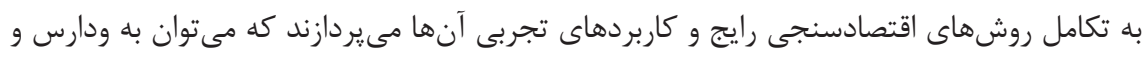

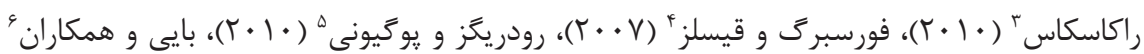
(T)

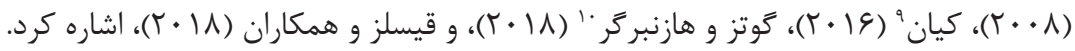

\section{الكوهاى جندمتغيره مانا با متغير هاى دوره تناوبى مختلط}

امكان تخمين مدلهاى ركرسيونى با وجود متغيرهايى با تواتر متفاوت و بهبود آشكار نتايج در

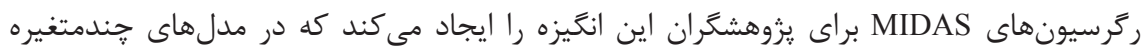

\section{Step Functions}

2. Partial Sums of High Frequency

3. Kvedaras \& Račkauskas

4. Forsberg \& Ghysels

5. Rodriguez \& Puggioni

6. Bai et al.

7. Pettenuzzo et al.

8. Zadrozny

9. Qian

10. Götz \& Hauzenberger 
نيز به دنبال گَترش روشهايى با متغيرهاى تناوب مختلط باشند. در مدلهاى جندمتغيره، مزيت

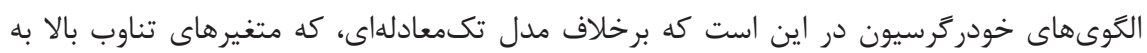

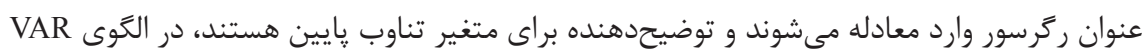
تمام متغيرها به شكل درونزا وارد الكو مىشوند و بازخورد تمام متغيرها بر يكديگر لحاظ مىشود. در

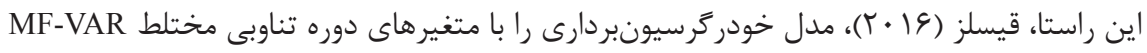

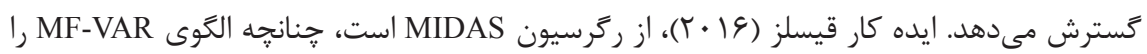
به شكل الكَى (ل) معرفى مى كند:

$$
\left[\begin{array}{c}
x_{H}\left(\tau_{L}, 1\right) \\
\vdots \\
x_{H}\left(\tau_{L}, m\right) \\
x_{L}\left(\tau_{L}\right)
\end{array}\right]=A_{0}+\sum_{j=1}^{p} A_{j}\left[\begin{array}{c}
x_{H}\left(\tau_{L-j}, 1\right) \\
\vdots \\
x_{H}\left(\tau_{L-j}, m\right) \\
x_{L}\left(\tau_{L-j}\right)
\end{array}\right]+\underline{\varepsilon}\left(\tau_{L}\right)
$$

كه الكَوى MF-VAR(p) است و در آن X $x_{L}$ نشاندهنده بردار متغير تناوب يايين با ابعاد K است

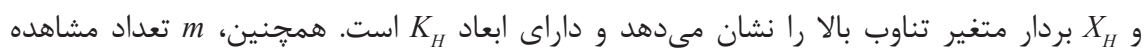

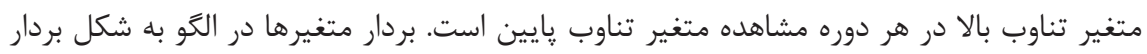

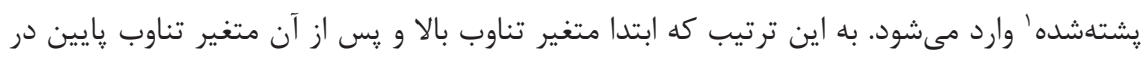

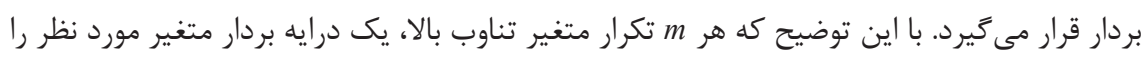

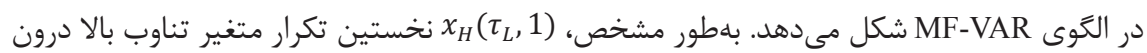
يك دوره از تناوب پايين است و (2) تناوب پايين است. با اين تعريف، بردار متغير الكَوى MF-VAR داراى ابعاد (m × بنابراين، آخرين معادله الكَى MF-VAR به شكل معادله (و) خواهد بود:

$$
\begin{aligned}
x_{L}\left(\tau_{L}\right)= & A_{0}^{m+1,1}+\sum_{j=1}^{p} A_{j}^{m+1, m+1} x_{L}\left(\tau_{L}-j\right)+ \\
& \sum_{j=1}^{p} \sum_{k=1}^{m} A_{j}^{m+1, k} x_{H}\left(\tau_{L}-j, k\right)+\underline{\varepsilon}\left(\tau_{L}\right)^{m+1,1}
\end{aligned}
$$

كه ملاحظه مىشود، شكلى از مدل رگرسيون MIDAS است. همانطور كه ييشتر اشاره شد،

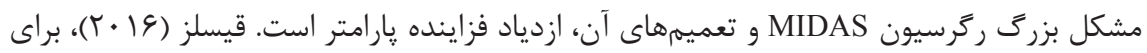

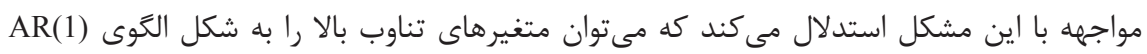


فرض كرد و بنابراين، در ماتريس ضرايب A بخش مربوط به ضرايب خودرگرسيونى متغير تناوب بالا

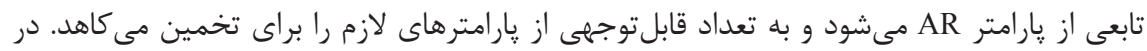

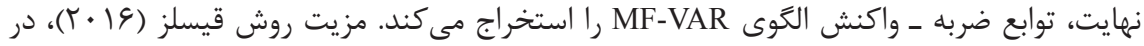
اين است كه امكان استفاده از مزاياى رايج الكوهاى خودرگرسيونبردارى VAR را براى متغيرهايى با

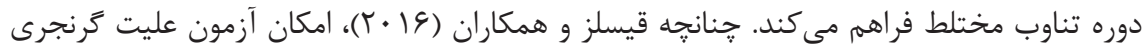

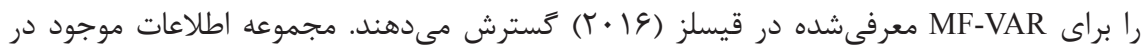

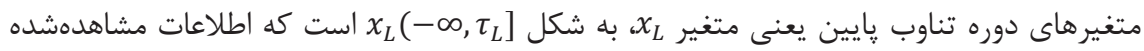

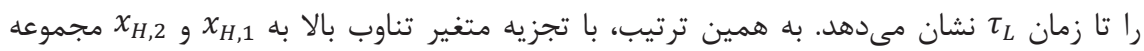
اطلاعات در دسترس دسترس را تا زمان $\tau_{L}$ با $\tau_{L}\left(\tau_{L}\right)=x_{L}\left(-\infty, \tau_{L}\right]+x_{H, 1}\left(-\infty, \tau_{L}\right]+x_{H, 2}\left(-\infty, \tau_{L}\right.$ اكنون يزوهشخران، نبود عليت گرنجرى را در الكوى MF-VAR به شكل زير تعريف مى كنند كه

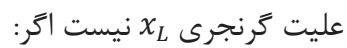

$P\left[x_{L}\left(\tau_{L}+h\right) \mid x_{L}\left(-\infty, \tau_{L}\right]+x_{H, 2}\left(-\infty, \tau_{L}\right]\right]=P\left[x_{L}\left(\tau_{L}+h\right) \mid \ell\left(\tau_{L}\right)\right] \forall \tau_{L} \in \mathbb{Z}$

يعنى مجموعه اطلاعات [ به همين ترتيب، $\left.P\left[x_{H, 1}\left(\tau_{L}+h\right) \mid x_{H, 1}\left(-\infty, \tau_{L}\right]+x_{H, 2}\left(-\infty, \tau_{L}\right]\right]=P\left[x_{H, 1}\left(\tau_{L}+h\right) \mid \ell\left(\tau_{L}\right)\right] \forall \tau_{L} \in \mathbb{Z}\right)$

يعنى در دسترس بودن يا نبودن مجموعه اطلاعات

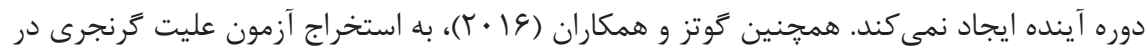

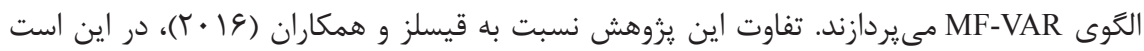
كه بهطور خاص براى حالتى كه تفاوت دوره تناوبى بين متغيرهاى حاضر در الكو زياد است، پاسخى

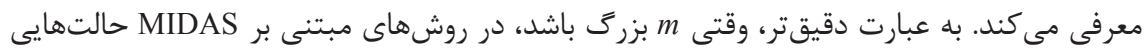

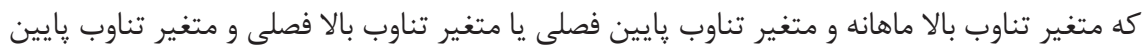

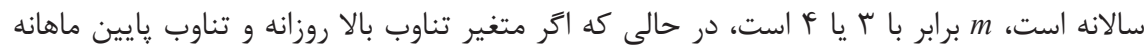

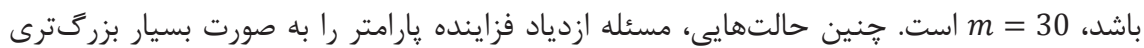




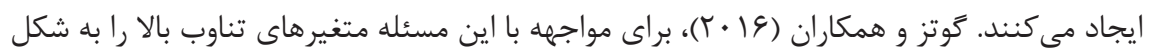
فرض مى كنند كه حالت كلىتر فرض AR(1) در يروهش قيسلز (19) • (Y) است. در ادامه قيسلز

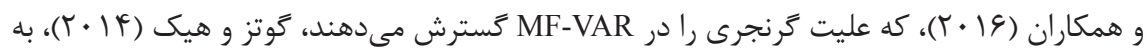
بررسى عليت آنى' در الكَى MF-VAR مى يردازند. براى اين منظور، الكَى (9) را در نظر مى كيرند: $A_{c} Z_{t}=A_{1} Z_{t-1}+\cdots+A_{p} Z_{t-p}+\varepsilon_{t}$

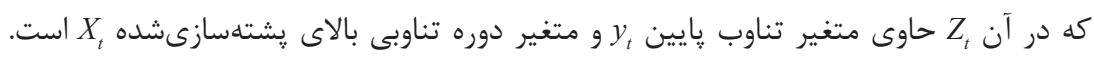
همجنين، مى دهد. فرم حلشده الكَى (9) عبارت است ازئ $Z_{t}=A_{1}^{*} Z_{t-1}+\cdots+A_{p}^{*} Z_{t-p}+u_{t}$

كه عليت كرنجرى و يس از آن، عليت آنى را بهطور شفافتر ارائه كنند، به تصريح يك مثال كلى با فرض

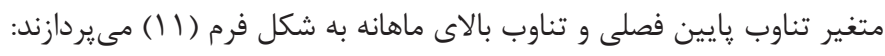
كه فرم حلشده آن نيز عبارت است از: $Z_{t}=\left(\begin{array}{cccc}\rho_{y}^{*} & \phi_{1}^{*} & \phi_{2}^{*} & \phi_{3}^{*} \\ \pi_{1}^{*} & a_{2.2}^{*} & a_{2.3}^{*} & a_{2.4}^{*} \\ \pi_{2}^{*} & a_{3.2}^{*} & a_{3.3}^{*} & a_{3.4}^{*} \\ \pi_{3}^{*} & a_{4.2}^{*} & a_{4.3}^{*} & a_{4.4}^{*}\end{array}\right) Z_{t-1}+u_{t}$

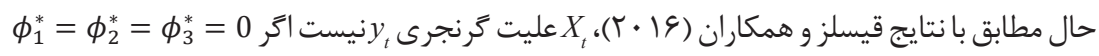


باشد. بلهور مشابه، $y_{t}$ عليت گرنجرى $X_{t}$ نيست اگر $\pi_{1}^{*}=\pi_{2}^{*}=\pi_{3}^{*}=0$ باشد. علاوه بر عليت كَرنجرى، يروهشكران نوعى عليت جديد را كه عليت آنى مىنامند، معرفى مى كنند. براى مرور تعريف

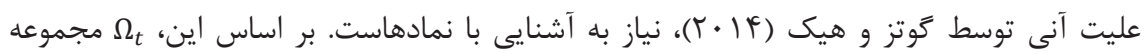
اطلاعات موجود در زمان t است، جنانجه اطلاعات همه فرايندهاى تصادفى بهجز W باشند. همجنين، بهترين بِيشبينى خطى

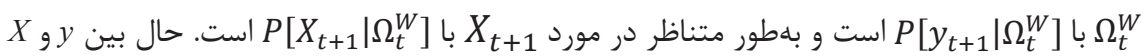

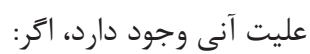

$P\left[y_{t+1} \mid \Omega_{t} \cup \Omega_{t+1}^{y}\right] \neq P\left[y_{t+1} \mid \Omega_{t}\right]$

$P\left[X_{t+1} \mid \Omega_{t} \cup \Omega_{t+1}^{X}\right] \neq P\left[X_{t+1} \mid \Omega_{t}\right]$

يعنى افزوده شدن اطلاعات درباره Xt+1 به مجموعه اطلاعات در دسترس در دوره t به بهبود ״يشبينى در دوره t ييشبينى

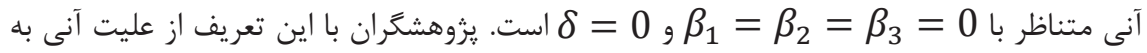
ارائه قيود متناظر براى فرم خلاصهشده درباره عليت آنى و فقدان عليت آنى مي يردازند.

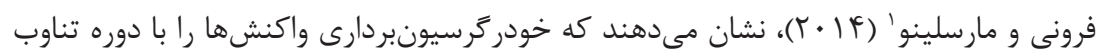
يكسان و با تورش برآورد مىكند كه اين موضوع به خاطر مشكل شناسايى شوكهاى ساختارى مارى

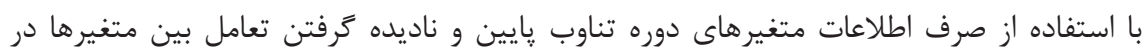

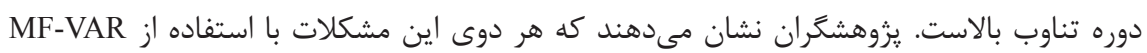

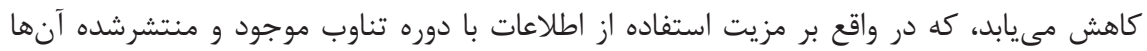

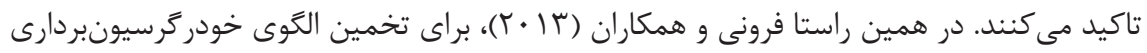
VAR با متغيرهاى دوره تناوبى مختلط از روشهاى كلاسيك و بيزى بهره ميى كيرند. آنها به كمك

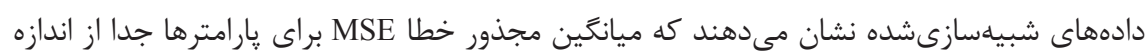

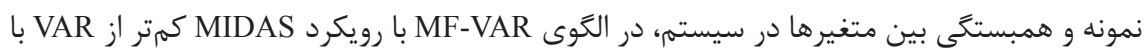

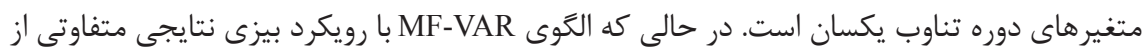
VAR با متغيرهاى دوره تناوبى يكسان ندارد. 
همانطور كه اشاره شد، گسترش الگوى خودرگرسيونبردارى براى متغيرهايى با دوره تناوبى مختلط، امكان بررسى ساير ويزّكىها را بر اساس الكوى MF-VAR فراهم مى كند. در همين راستا

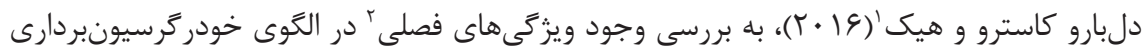

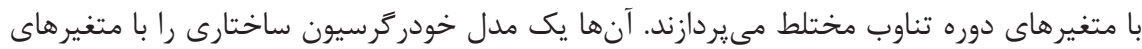

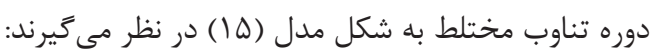

$A_{c} Z_{t}=\widetilde{\Theta} D_{t}+A_{1} Z_{t-1}+\cdots+A_{p} Z_{t-p}+\varepsilon_{t}$

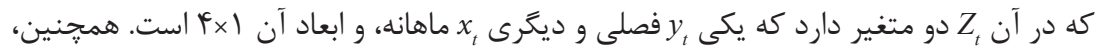
$D_{t}=\iota_{\frac{T}{4}} \otimes I_{4}$ هن

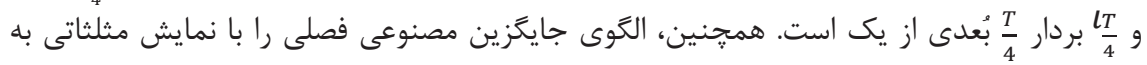
شكل الكوى (19) معرفى مى كند:

$Z_{t}=\Psi T_{t}+\Phi_{1} Z_{t-1}+\varepsilon_{t}$

كه در آن [T يكى الكوى MF-VAR مرتبه P با استفاده از ماتريس R با آزمون والد زير بررسى مى كنند.

$\xi_{w}=[\operatorname{Rvec}(\widehat{\Pi})]^{\prime}(R \widehat{\Sigma} R)^{-1}[\operatorname{Rvec}(\widehat{\Pi})]$

كه ي $W=\left(W_{1}, \cdots, W_{T}\right)^{\prime}$ و $Z^{\prime} W\left(W^{\prime} W\right)^{-1}$ ركرسورها متناظر با 'ر

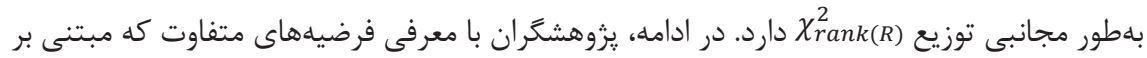

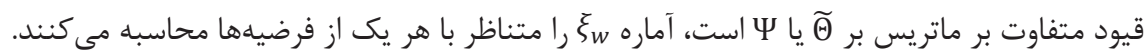
سرانجام، جار جوب آزمون ارائهشده را روى متغيرهاى اشتغال فصلى و ورودى گردششخران ماهانه بكار مى برند. يروهشهاى سرىهاى زمانى با دوره تناوبى مختلط بردارى بلهور بسيار گستردهاى در حال

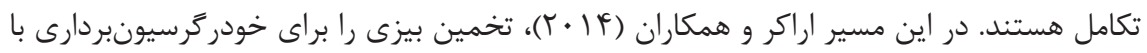




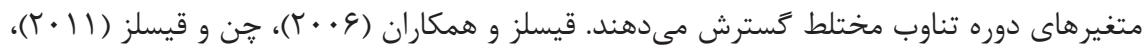

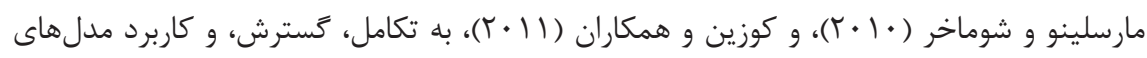
سرىهاى زمانى جندمتغيره با دوره تناوبى مختلط مىيردازند. نياز به اشاره است كه يزوهشگران در سرىهاى زمانى با دوره تناوبى مختلط بردارى، علاوه بر تكامل و گسترش رويكردهاى رايج

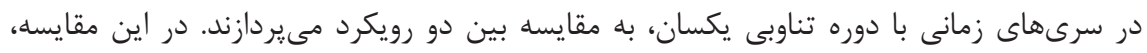

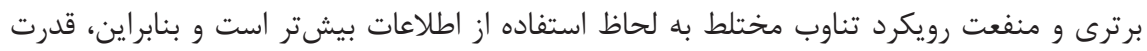
توضيحدهندگى و بيش بينى بيشتر در تخمين، و كارايى بيشتر در توزيع را در مقابل هزينه يِيجيد

بيشتر به نمايش مى تذارند.

\section{همانباشتخى تكمعادلهاى با متغيرهاى دوره تناوبى مختلط}

همانطور كه از ابتداى اين يزوهش دنبال شده است، تاكنون يزوهشهاى گستردهاى در خصوص طراحى الكوهايى با حضور متغيرها از دوره تناوبى متفاوت صورت كرفته است. با اين حال، بايد اشاره

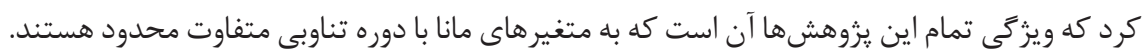
يزوهشهاى اندكى در شاخهُ سرىهاى زمانى با دوره تناوبى متفاوت به متغيرهاى انباشته از مرتبه

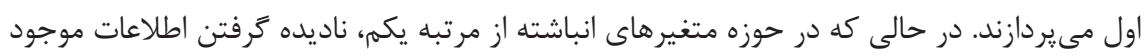

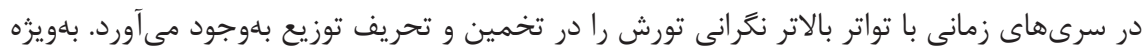
در مورد متغيرهاى انباشته از مرتبه يكمم اين احتمال وجود دارد كه تجميع زمانى به حذف به حركات

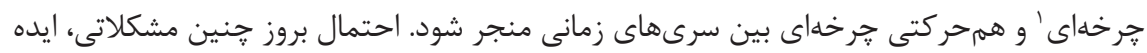

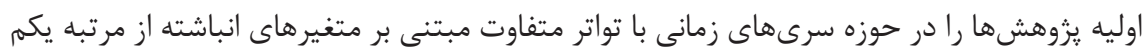

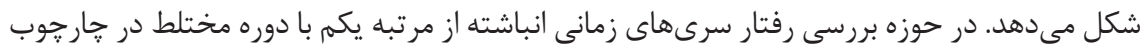

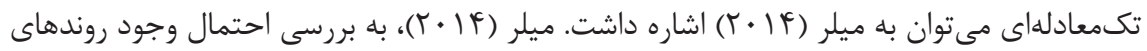

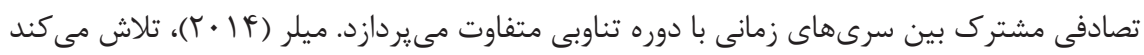

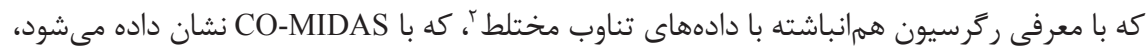

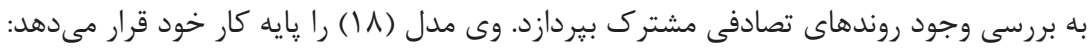


$y_{t+1}=\rho y_{t}+\beta^{\prime} \sum_{k=0}^{m-1} \pi_{k+1} x_{t+1-\frac{k}{m}}^{(m)}+\varepsilon_{t+1}$

كه مشابه قبل m نشاندهنده تعداد مشاهده متغير تناوب بالا در يك دوره تكرار تناوب يايين

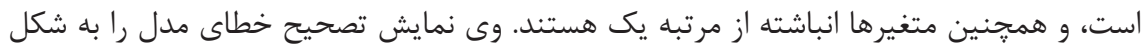

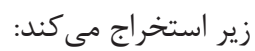

$\Delta y_{t+1}=(\rho-1) y_{t}+\beta^{\prime} x_{t+1}-\beta^{\prime} \pi(L) \Delta^{(1 / m)} x_{t+1}^{(m)}+\varepsilon_{t+1}$

كه

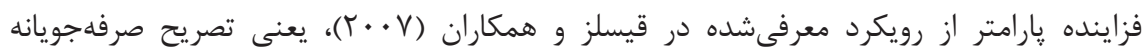

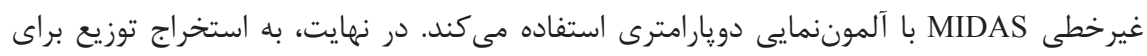

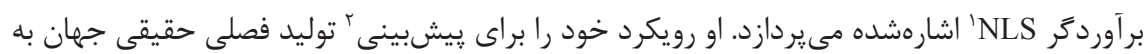

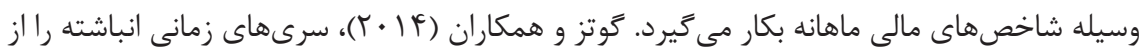

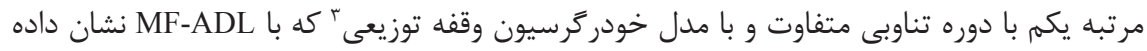

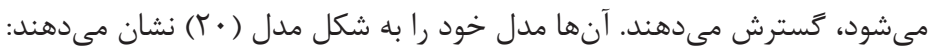

$$
A(L) y_{t}^{(m)}=c+B_{0}\left(L^{1 / m}\right) x_{t}^{(m)}+B_{1}\left(L^{1 / m}\right) x_{t-1}^{(m)}+\cdots+B_{q l}\left(L^{1 / m}\right) x_{t-q l}^{(m)}+\varepsilon_{t}^{(m)}
$$

كه فرض مى شود و

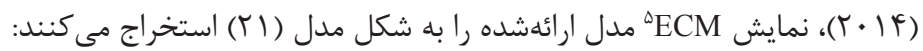

$A^{*}(L) \Delta y_{t}=c-A(1)\left[y_{t-1}-\frac{\sum_{j=0}^{q l} B_{j}(1)}{A(1)} L^{i / m} \chi_{t-1}^{(m)}\right]+B^{*}\left(L^{1 / m}\right) \Delta^{(1 / m)} \chi_{t}^{(m)}+\varepsilon_{t}$

كه

1. Nonlinear Least Square

2. Nowcasting

3. Autoregressive Distributed Lag Model

19

4. Martingale Difference Sequence

5. Error Correction Model 
از فرايند دومرحلهاى انكل و كرنجر' استفاده مى كنند. يعنى

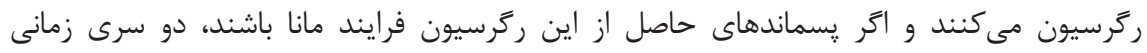

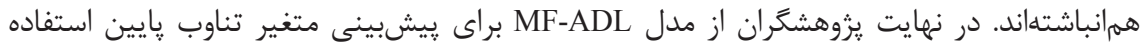

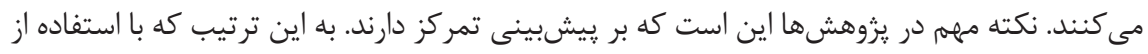

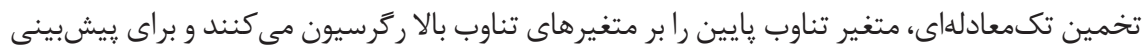

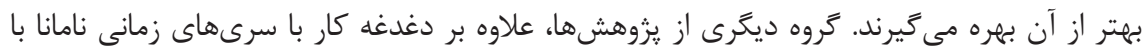

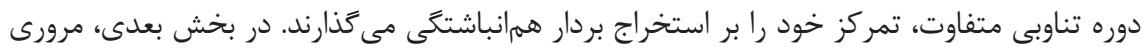

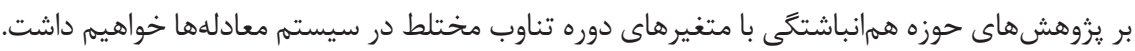

\section{همانباشتكى با متغيرهاى دوره تناوب مختلط در سيسته جندمتغيره}

بررسى رفتار بلندمدت سرىهاى زمانى انباشته از مرتبه يكم دوره تناوب مختلط به صورت

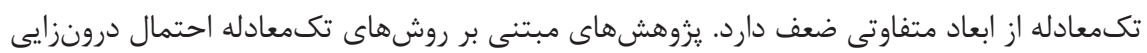

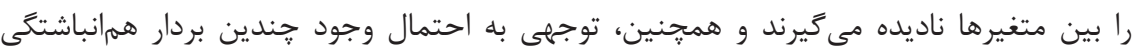
ندارند. از اينرو، يزوهشگران حوزه متغيرهاى دوره تناوب مختلط به سمت رفع اين مسئله كام

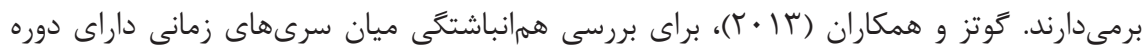

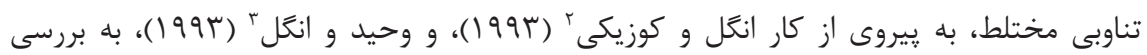
وجود ويزگى روند مشترك و جرخه مشترك بين سرىهاى زمانى انباشته از مرتبه يكمم، در زمانى

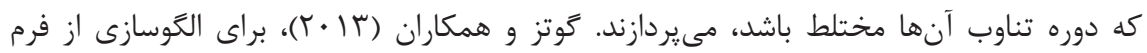

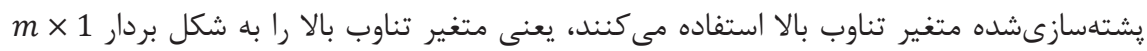
بعدى يعنى بالاست، به شكل ${ }^{\prime}$

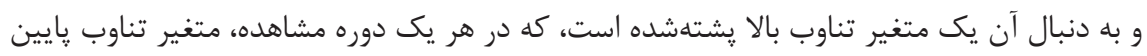
m بار مشاهده مىشود. حال از متغير 
ابعاد 1 × (1 + (m) است. آنها نشان مى دهند كه با سرىهاى زمانى ناماناى تناوب مختلط به شكل بردار Z معرفىشده، دو دسته روابط بلندمدت مى متوان بين متغيرها يافت: ا. رابطه بلندمدت درون

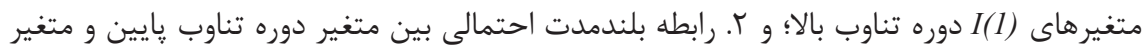
دوره تناوب بالا. تحت شرايطى كه رابطه بلندمدت دوم وجود نداشته باشد، مى توان با تفاضل كرفتن از

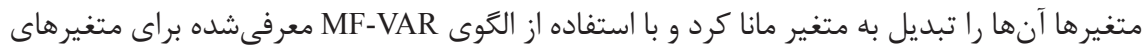

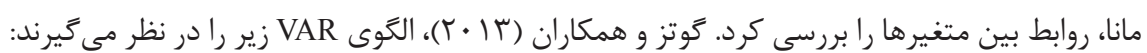

$Z_{t}=\Gamma_{1} Z_{t-1}+\cdots+\Gamma_{p} Z_{t-p}+\varepsilon_{t}$

كه 'VECM ع است. آنها الخوى يادشده را با نمايش بازنويسى مى كنند. يعنى:

$\Delta Z_{t}=\tilde{\Gamma}_{1} \Delta Z_{t-1}+\cdots+\tilde{\Gamma}_{p-1} \Delta Z_{t-p+1}+\Pi Z_{t-1}+\varepsilon_{t}$

كه عبارت از 1 rank $(\Pi)=\left(r_{0}+r_{1}\right)<m+1$ است. رتبه همانباشتگى را مجموع دو نوع رابطه بلندمدت

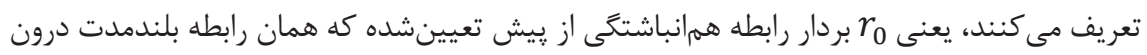
متغير تناوب بالاست، و دستبالا مىتوان 1 - m رابطه بلندمدت از يُش رِيش تصريحشده متصور شد. براى

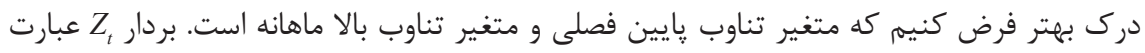

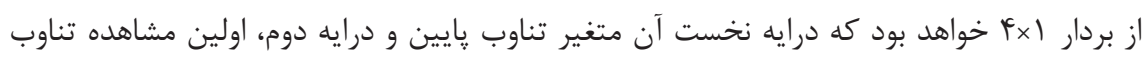

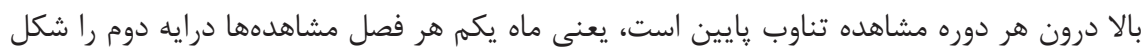

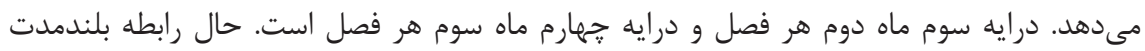

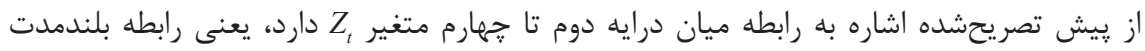
درون متغير تناوب بالا كه از لحاظ شهودى بهطور كامل دركيذير است. يكى متغير ماهانه انتظار

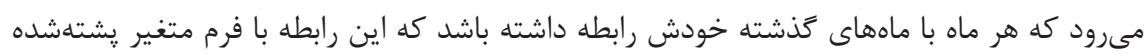

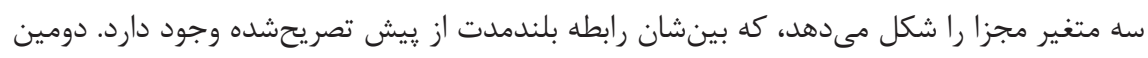

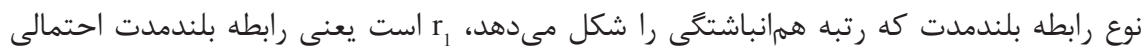


بين متغير تناوب پايين و متغير تناوب بالا. اين نوع رابطه بلندمدت ناشناخته است و در آزمون است.

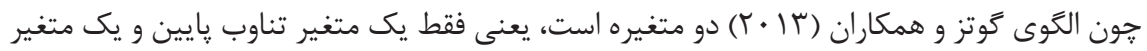
تناوب بالا، يس دستبالا احتمال وجود يك رابطه بلندمدت ناشناخته بين دو متغير امكانيذير است. در موردى كه بين دو متغير تناوب بالا و تناوب يايين هم|نباشتگى وجود ندارد، رتبه همانباشتگى در مدل VECM دومتغيره ارائهشده عبارت از 1 - ل است. زمانى كه بين دومتغير يادشده همانباشتگى وجود دارد، رتبه هم|نباشتكى عبارت از

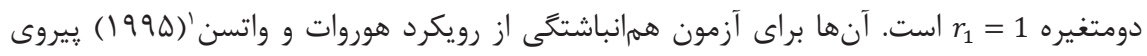

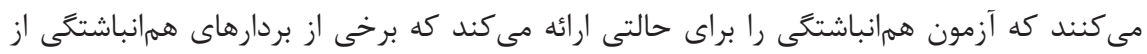

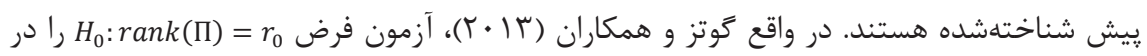
مقابل مى يردازند. فرايند آزمون به اين صورت است كه:

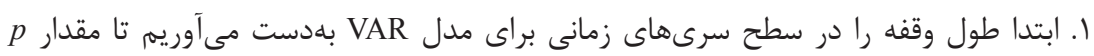

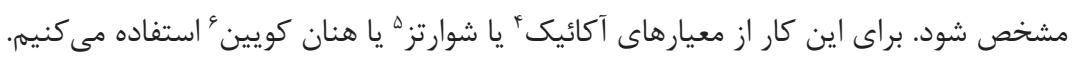

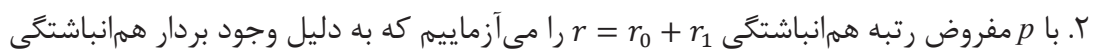
از ييش تصريحشده، متكى بر روش هوروات و واتسن (199ه (1) است.

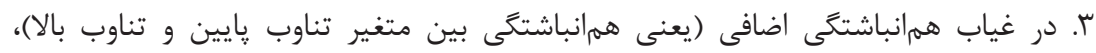

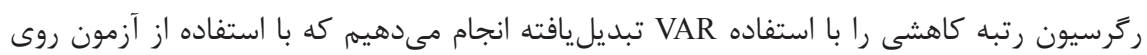
مقادير ويره صفر بهدستآمده از تحليل همبستكى كانونى به شكل زير است: cancor $\left\{\Delta Z_{t}^{*},\left(\begin{array}{c}\Delta Z_{t-1}^{*} \\ \vdots \\ \Delta Z_{t-p+1}^{*} \\ \tilde{Z}_{t-p}^{0}\end{array}\right)\right\}$

كه $\operatorname{cancor}\left\{V_{t}, W_{t}\right.$ رابطه همبستگى كانونى بين $V_{t}$ و است و:

1. Horvath \& Watson

2. Common Trend

3. Common Cycle

4. Akaike Info Criterion

5. Schwarz Criterion

6. Hannan-Quinn Criterion 
$\Delta Z_{t}^{*}=\left(\begin{array}{c}\Delta y_{t} \\ \Delta^{\left(\frac{1}{m}\right)} x_{t}^{(m)} \\ \vdots \\ \Delta_{\left(\frac{1}{m}\right)}^{(m)} x_{t-\frac{m-2}{m}}^{(m)} \\ \Delta^{\left(\frac{1}{m}\right)} x_{t-\frac{m-1}{m}}^{(m)}\end{array}\right), \tilde{Z}_{t}=\left(\begin{array}{c}y_{t} \\ \Delta^{\left(\frac{1}{m}\right)} x_{t}^{(m)} \\ \vdots \\ \Delta^{\left(\frac{1}{m}\right)^{(m)}} \\ x_{t-\frac{m-2}{m}}^{(m)} \\ x_{t-\frac{m-1}{m}}^{(m)}\end{array}\right), \tilde{\varepsilon}_{t}=\left(\begin{array}{c}\varepsilon_{t, y} \\ \Delta^{\left(\frac{1}{m}\right)} \varepsilon_{t}^{(m)} \\ \vdots \\ \Delta^{\left(\frac{1}{m}\right)} \varepsilon_{t-\frac{m-2}{m}}^{(m)} \\ \varepsilon_{t-\frac{m-1}{m}}^{(m)}\end{array}\right)$

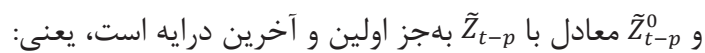

$\tilde{Z}_{t-p}^{0}=\left(\begin{array}{c}0 \\ \Delta^{\left(\frac{1}{m}\right)} x_{t-p}^{(m)} \\ \vdots \\ \Delta^{\left(\frac{1}{m}\right)} x_{t-p-\frac{m-2}{m}}^{(m)} \\ 0\end{array}\right)$

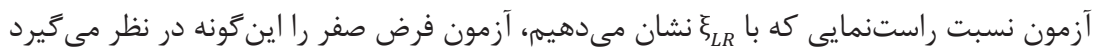

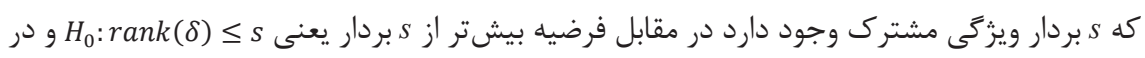

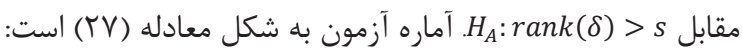

$\xi_{L R}=-T \sum_{i=1}^{S} \ln \left(1-\hat{\lambda}_{i}\right)$

كه

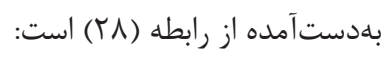

$\hat{\Sigma}_{V V}^{-1} \hat{\Sigma}_{V W} \hat{\Sigma}_{W W}^{-1} \hat{\Sigma}_{W V}$

$$
\text { كه }
$$

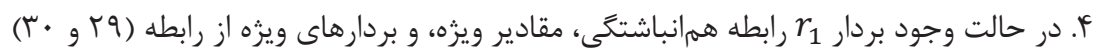

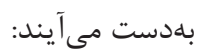
cancor $\left\{\Delta Z_{t}^{*},\left(\begin{array}{c}\Delta Z_{t-1}^{*} \\ \vdots \\ \Delta Z_{t-p+1}^{*} \\ \tilde{Z}_{t-p}\end{array}\right)\right\}$ 
$\tilde{Z}_{t-p}=\left(\begin{array}{c}y_{t-p} \\ \Delta^{\left(\frac{1}{m}\right)} x_{t-p}^{(m)} \\ \vdots \\ \Delta^{\left(\frac{1}{m}\right)} x_{t-p-\frac{m-2}{m}}^{(m)} \\ x_{t-p-\frac{m-1}{m}}^{(m)}\end{array}\right)$

كه

است. با وجود اين كه گوتز و همكاران (rا • r)، به مسئله درونزايى توجه دارند و به صورت

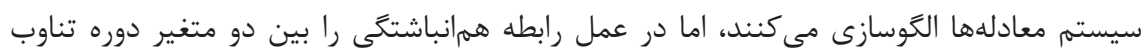

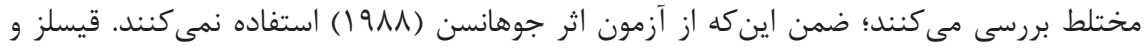

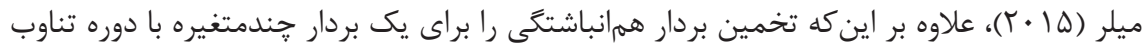

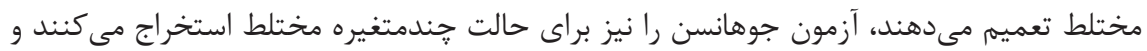

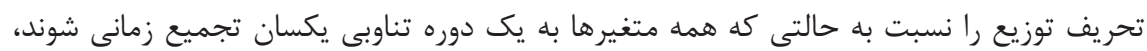

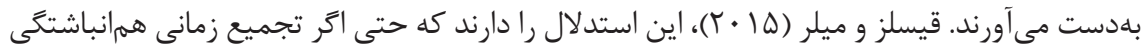

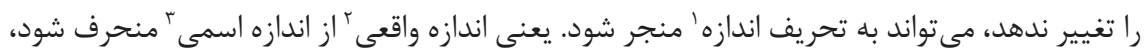

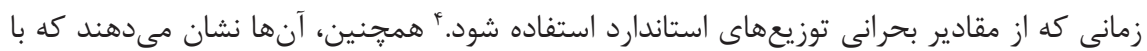

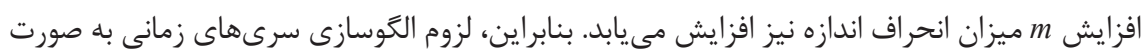
مختلط را بيش از مسئله از دست رفتن اطلاعات مىدانند و مدعىاند كه اعتبار استنباط آمارى نيز

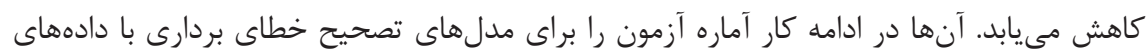

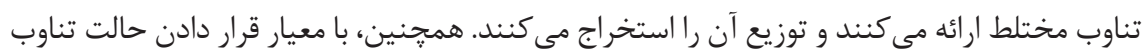
مشترك به مقايسه نتايج الكوى تناوب مختلط با تناوب يكسان مى يردازند. آماره آزمونى كه قيسلز

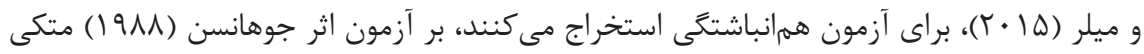

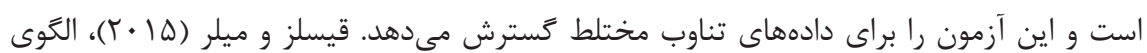

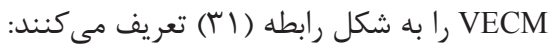

1. Size Distortion

2. Actual Size

3. Nominal Size

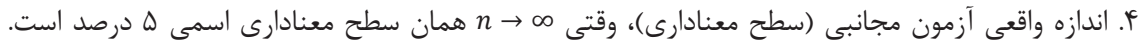

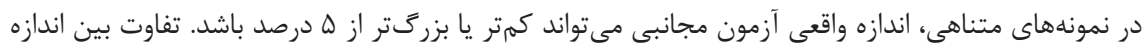

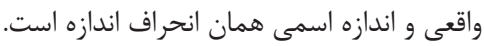


$\Delta z_{t}^{m}=\Gamma^{m} A^{m^{\prime}} z_{t-1}^{m}+\eta_{t}^{m}$

كن كه مختلط ارائهشده شامل

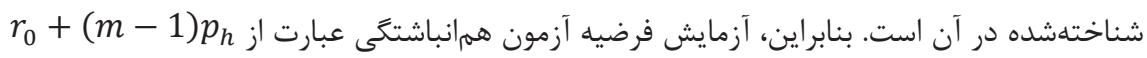

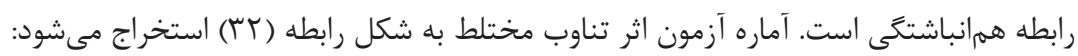

$$
\begin{aligned}
-2 \log Q\left(H_{r_{0}+(m-1) p_{h} \mid p_{l}+m p_{h}}\right) & =-T \sum_{i=r_{0}+(m-1) p_{h}+1}^{p_{l}+m p_{h}} \log \left(1-\hat{\lambda}_{i}\right) \\
& =\operatorname{Ttr}\left\{\left(R_{11}^{m}\right)^{-1} R_{10}^{m}\left(R_{00}^{m}\right)^{-1} R_{01}^{m}\right\}+o_{P}(1)
\end{aligned}
$$

${ }_{g} r_{0 t}=\Delta z_{t}$ ك $g, h=0,1$ ك به $R_{g h}=T^{-1} \sum_{t=1}^{T} r_{g t} r_{h t}^{\prime}, R_{g h}^{m}=\Pi_{m} R_{g h} \Pi_{m}^{\prime}$

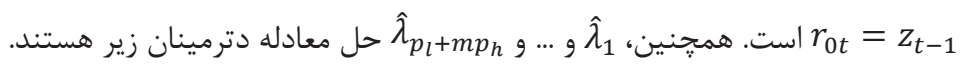

$\left|\lambda I-\left(R_{11}^{m}\right)^{-1} R_{10}^{m}\left(R_{00}^{m}\right)^{-1} R_{01}^{m}\right|=0$

ملاحظه مىشود كه مسئله وجود بردار همانباشتخى از يِيش تعيينشده با تعديل فرض صفر

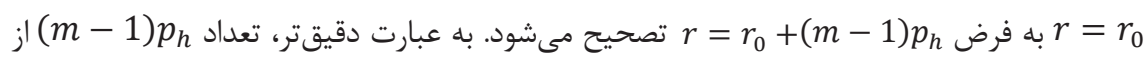

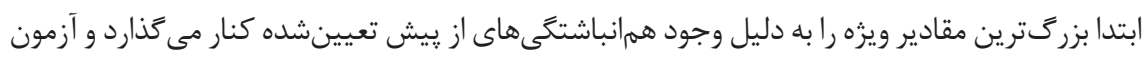

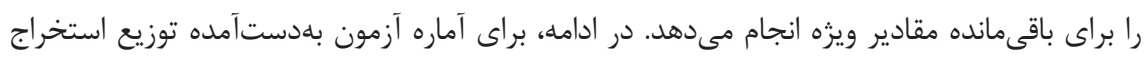
مي كند. با فرضيه وجود است، آماره آزمون اثر به شكل زير خواهد بود:

$$
\begin{aligned}
& \operatorname{tr}\left\{\Xi_{10}^{m}{ }^{\prime}\left(\Xi_{11}^{m}\right)^{-1} \Xi_{00}^{m}\left(\Xi_{00}^{m}\right)^{-1}\right\} \\
& \Xi_{00}^{m}=\Pi_{m}\left(\Sigma \otimes m^{-1} H_{00}\right) \Pi_{m}^{\prime}
\end{aligned}
$$


$\Xi_{11}^{m}=\Pi_{m}\left(\Sigma^{\frac{1}{2}} \int W W^{\prime} \Sigma^{\Sigma^{\frac{1}{2}}} \otimes u^{\prime}\right) \Pi_{m}^{\prime}$

$\Xi_{10}^{m}=\Pi_{m}\left(\Sigma^{\frac{1}{2}} \int W d W^{\prime} \Sigma^{\frac{1^{\prime}}{2}} \otimes u^{\prime}+\left(\Sigma \otimes m^{-1} H_{10}\right)\right) \Pi_{m}^{\prime}$

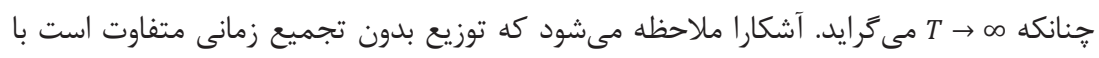

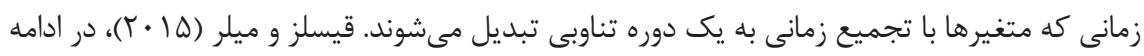

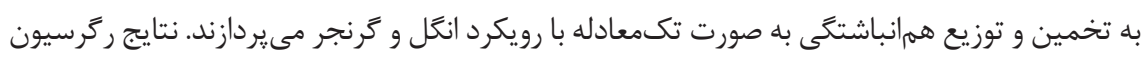

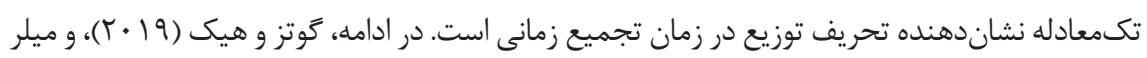

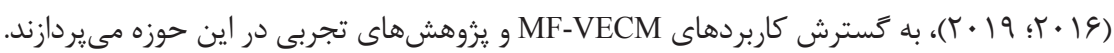

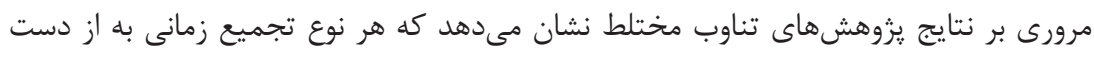

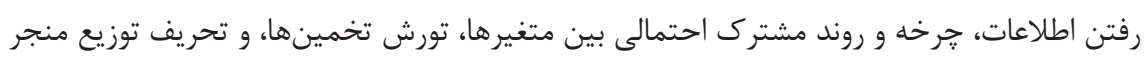

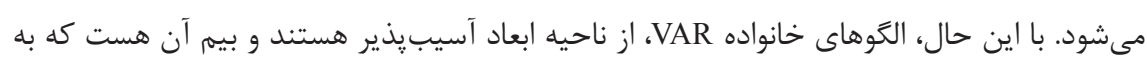

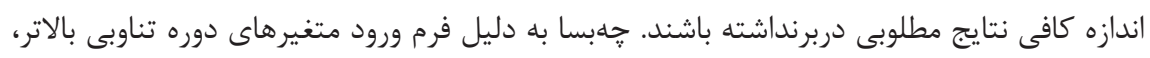

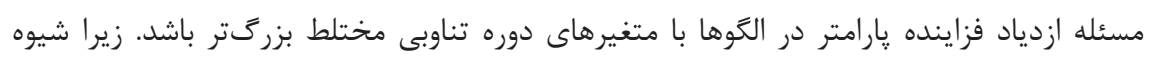

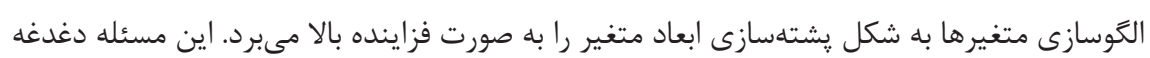

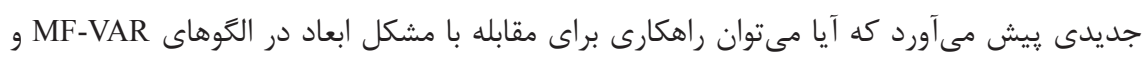

\section{بحث و نتيجه كيرى}

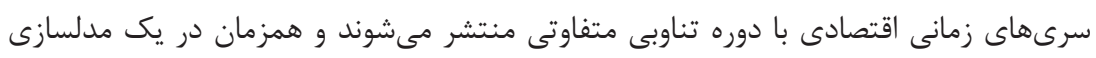

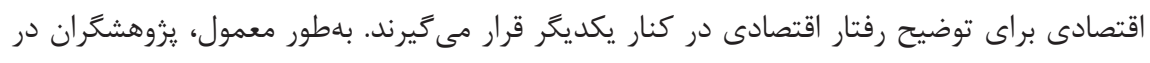

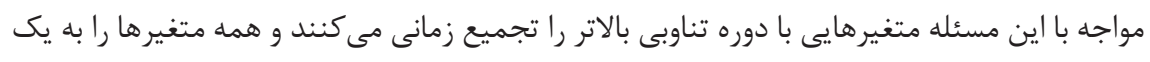

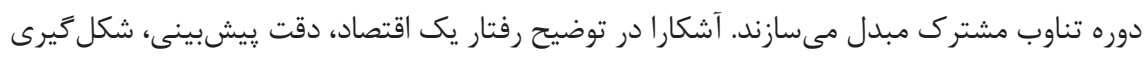

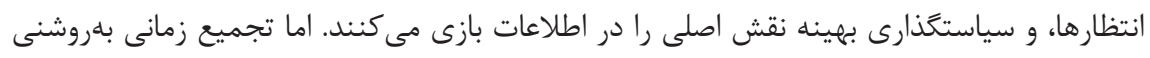

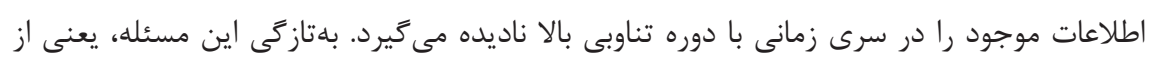

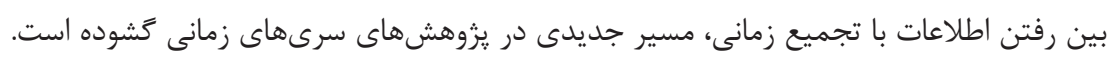

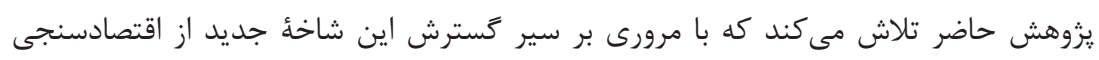


سرىهاى زمانى به ير كردن شكاف موجود در ادبيات نظرى سرىهاى زمانى با متغيرهاى دوره

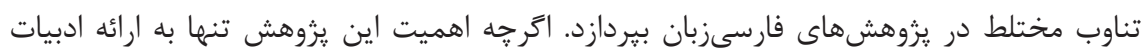

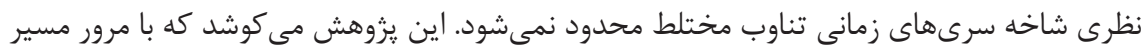
پيشرفت ادبيات مدلهاى تناوب مختلط به شناسايى قابليتها و محدوديتهاى هر يك از الكوها

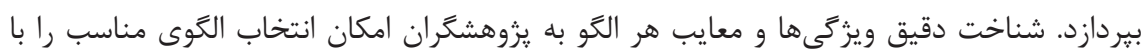
ويزگ كى هاى خاص آن فراهم مى كند.

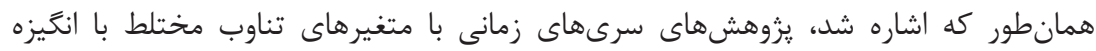

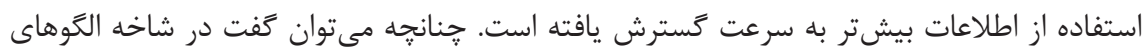
اقتصادسنجى با متغيرهاى مانا مسير تكاملى بلهسرعت ييش مىرود و در حال حاضر، امكان تخمين بسيارى از روشها با استفاده از دادههايى با دوره تناوبى مختلط ميسر است. در ادامه، در شاخه

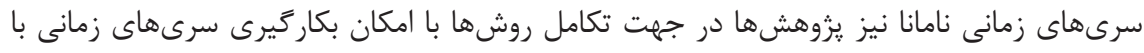

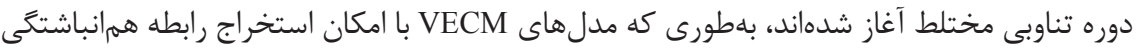

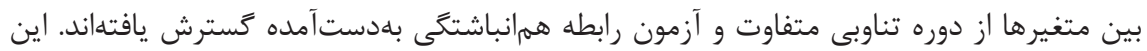

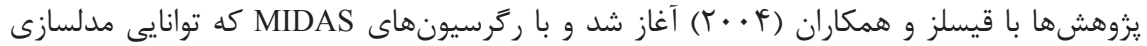

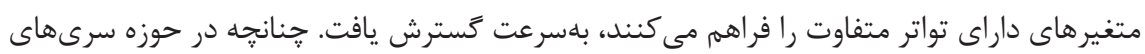

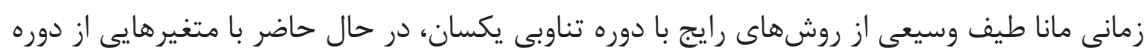
تناوبى متفاوت كاربرديذير است. يزوهشهاى مبتنى بر متغيرهاى دوره تناوبى مختلط، علاوه بر اين كه امكان استفاده از اطلاعات بيشتر را فراهم مى كنند، آشكار مى كنند كه تجميع زمانى در مواردى به مديه

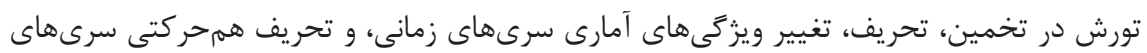

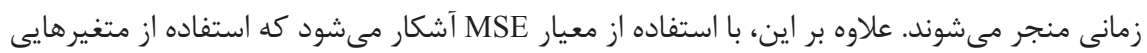
با دوره تناوبى متفاوت بدون تجميع زمانى، كارايى را در مدلسازى اقتصادى افزايش مىدهد.

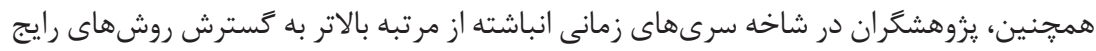

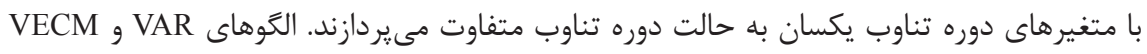

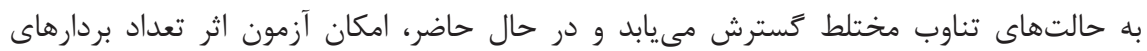

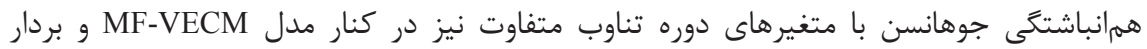

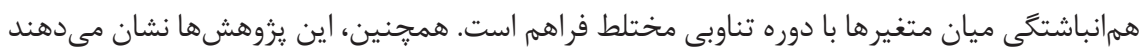

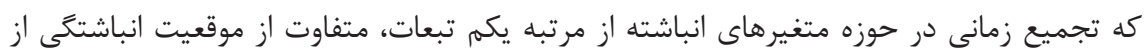




$$
\begin{aligned}
& \text { مرتبه صفر است. جنانجه بهرغم اين كه بردار هممانباشتگى با تجميع زمانى با تورش مواجه نمىشود، }
\end{aligned}
$$

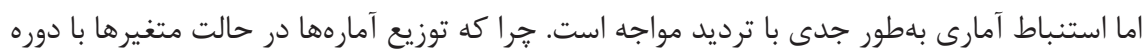

$$
\begin{aligned}
& \text { تناوبى متفاوت بهطور كامل با توزيع در زمان تجميع زمانى و تبديل به يك دوره تناوب يكسان متفاوت بهات } \\
& \text { است. به عبارت دقيقتر، تجميع زمانى توزيع را تحريف مى كند و بنابراين، استنباط آمارى هنگام } \\
& \text { تجميع زمانى بىاعتبار است. }
\end{aligned}
$$

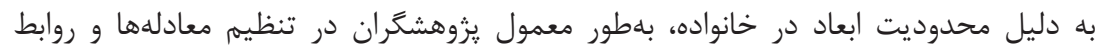$$
\text { اقتصادى مورد بررسى ناگزير به محدود كردن متغيرهاى واردشده در مدل هستند، جدا از اين كه از }
$$

متغيرهايى با تواتر مختلف استفاده شود يا تواتر يكسان (به واسطه تجميع زمانى). اين موضوع به به مرديه

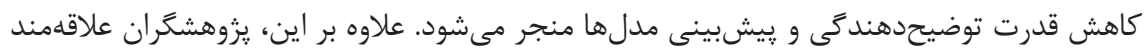
مى توانند در شاخه متغيرهايى با مرتبه انباشتكى از درجه دوم به كسترش ادبيات نظرى سرىهاى زمانى با متغيرهاى تناوب مختلط بيردازند و شكاف را در اين شاخه از ادبيات ير كنند.

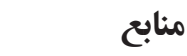

Amemiya, T., \& Wu, R. Y. (1972). The Effect of Aggregation on Prediction in the Autoregressive Model. Journal of the American Statistical Association, 67(339), 628-632.

Andreou, E., Ghysels, E., \& Kourtellos, A. (2010). Regression Models with Mixed Sampling Frequencies. Journal of Econometrics, 158(2), 246-261.

Bai, J., Ghysels, E., \& Wright, J. H. (2013). State Space Models and MIDAS Regressions. Econometric Reviews, 32(7), 779-813.

Breitung, J., \& Swanson, N. R. (2002). Temporal Aggregation and Spurious Instantaneous Causality in Multiple Time Series Models. Journal of Time Series Analysis, 23(6), 651-665.

Chambers, M. J. (2019). Frequency Domain Estimation of Continuous Time Co-Integrated Models with Mixed Frequency and Mixed Sample Data. Journal of Time Series Analysis, 40(6), 887-913.

Chen, X., \& Ghysels, E. (2011). News-Good or Bad-and Its Impact on Volatility Predictions Over Multiple Horizons. The Review of Financial Studies, 24(1), 46-81.

Clements, M. P., \& Galvão, A. B. (2008). Macroeconomic Forecasting with Mixed-Frequency Data: Forecasting Output Growth in the United States. Journal of Business \& Economic Statistics, 26(4), 546-554.

Del Barrio Castro, T., \& Hecq, A. (2016). Testing for Deterministic Seasonality in MixedFrequency VARs. Economics Letters, 149(1), 20-24.

Engle, R. F., \& Kozicki, S. (1993). Testing for Common Features. Journal of Business \& 
Economic Statistics, 11(4), 369-380.

Eraker, B., Chiu, C. W., Foerster, A. T., Kim, T. B., \& Seoane, H. D. (2014). Bayesian Mixed Frequency VARs. Journal of Financial Econometrics, 13(3), 698-721.

Foroni, C., \& Marcellino, M. (2014). Mixed-Frequency Structural Models: Identification, Estimation, and Policy Analysis. Journal of Applied Econometrics, 29(7), 1118-1144.

Foroni, C., Ghysels, E., \& Marcellino, M. (2013). Mixed-Frequency Vector Autoregressive Models. Advances in Econometrics, 32(1), 247-272.

Forsberg, L., \& Ghysels, E. (2007). Why Do Absolute Returns Predict Volatility So Well? Journal of Financial Econometrics, 5(1), 31-67.

Ghysels, E. (2016). Macroeconomics and the Reality of Mixed Frequency Data. Journal of Econometrics, 193(2), 294-314.

Ghysels, E., \& Miller, J. I. (2015). Testing for Co-Integration with Temporally Aggregated and Mixed-Frequency Time Series. Journal of Time Series Analysis, 36(6), 797-816.

Ghysels, E., \& Wright, J. H. (2009). Forecasting Professional Forecasters. Journal of Business \& Economic Statistics, 27(4), 504-516.

Ghysels, E., Hill, J. B., \& Motegi, K. (2016). Testing for Granger Causality with Mixed Frequency Data. Journal of Econometrics, 192(1), 207-230.

Ghysels, E., Hill, J. B., \& Motegi, K. (2018). Testing a Large Set of Zero Restrictions in Regression Models, With An Application to Mixed Frequency Granger Causality. Workshop on Advances in Econometrics 2017 at Hakodate.

Ghysels, E., Santa-Clara, P., \& Valkanov, R. (2004). The MIDAS Touch: Mixed Data Sampling Regression Models. CIRANO Working Papers 2004s-20, CIRANO, Montreal, Canada.

Ghysels, E., Santa-Clara, P., \& Valkanov, R. (2005). There is a Risk-Return Trade-Off After All. Journal of Financial Economics, 76(3), 509-548.

Ghysels, E., Santa-Clara, P., \& Valkanov, R. (2006). Predicting Volatility: Getting the Most Out of Return Data Sampled at Different Frequencies. Journal of Econometrics, 131(1-2), 59-95.

Ghysels, E., Sinko, A., \& Valkanov, R. (2007). MIDAS Regressions: Further Results and New Directions. Econometric Reviews, 26(1), 53-90.

Götz, T. B., \& Hecq, A. (2014). Nowcasting Causality in Mixed Frequency Vector Autoregressive Models. Economics Letters, 122(1), 74-78.

Götz, T. B., \& Hecq, A. W. (2019). Granger Causality Testing in Mixed-Frequency VARs with Possibly (Co) Integrated Processes. Journal of Time Series Analysis, 40(6), 914-935.

Götz, T. B., Hecq, A., \& Smeekes, S. (2016). Testing for Granger Causality in Large Mixed-Frequency VARs. Journal of Econometrics, 193(2), 418-432.

Götz, T. B., Hecq, A., \& Urbain, J. P. (2014). Forecasting Mixed-Frequency Time Series with ECM-MIDAS Models. Journal of Forecasting, 33(3), 198-213.

Götz, T. B., Hecq, A., \& Urbain, J.-P. (2013). Testing for Common Cycles in Non-Stationary VARs with Varied Frequency Data, VAR Models in Macroeconomics-New Developments and Applications: Essays in Honor of Christopher A. Sims (Advances in Econometrics, Volume 32): Emerald Group Publishing Limited.

Götz, T., \& Hauzenberger, K. (2018). Large Mixed-Frequency VARs with a Parsimonious Time-Varying Parameter Structure. Deutsche Bundesbank Discussion Paper 40/2018. 
Horvath, M. T., \& Watson, M. W. (1995). Testing for Co-Integration When Some of the |Co-Integrating Vectors are Prespecified. Econometric Theory, 11(5), 984-1014.

Johansen, S. (1988). Statistical Analysis of Co-Integration Vectors. Journal of Economic Dynamics and Control, 12(2-3), 231-254.

Kuzin, V., Marcellino, M., \& Schumacher, C. (2011). MIDAS vs. Mixed-Frequency VAR: Nowcasting GDP in the Euro Area. International Journal of Forecasting, 27(2), 529-542.

Kvedaras, V., \& Račkauskas, A. (2010). Regression Models with Variables of Different Frequencies: The Case of a Fixed Frequency Ratio. Oxford Bulletin of Economics and Statistics, 72(5), 600-620.

Lütkepohl, H. (1984). Forecasting Contemporaneously Aggregated Vector ARMA Processes. Journal of Business \& Economic Statistics, 2(3), 201-214.

Marcellino, M. (1999). Some Consequences of Temporal Aggregation in Empirical Analysis. Journal of Business \& Economic Statistics, 17(1), 129-136.

Marcellino, M., \& Schumacher, C. (2010). Factor MIDAS for Nowcasting and Forecasting With Ragged-Edge Data: A Model Comparison for German GDP. Oxford Bulletin of Economics and Statistics, 72(4), 518-550.

Miller, J. I. (2014). Mixed-Frequency Co-Integrating Regressions with Parsimonious Distributed Lag Structures. Journal of Financial Econometrics, 12(3), 584-614.

Miller, J. I. (2016). Conditionally Efficient Estimation of Long-Run Relationships Using Mixed-Frequency Time Series. Econometric Reviews, 35(6), 1142-1171.

Miller, J. I. (2019). Testing Co-Integrating Relationships Using Irregular and NonContemporaneous Series with an Application to Paleoclimate Data. Journal of Time Series Analysis, 40(6), 936-950.

Pettenuzzo, D., Timmermann, A., \& Valkanov, R. (2016). A MIDAS Approach to Modeling First and Second Moment Dynamics. Journal of Econometrics, 193(2), 315-334.

Qian, H. (2016). A Computationally Efficient Method for Vector Auto-Regression with Mixed Frequency Data. Journal of Econometrics, 193(2), 433-437.

Rodriguez, A., \& Puggioni, G. (2010). Mixed Frequency Models: Bayesian Approaches to Estimation and Prediction. International Journal of Forecasting, 26(2), 293-311.

Schorfheide, F., \& Song, D. (2015). Real-Time Forecasting with a Mixed-Frequency VAR. Journal of Business \& Economic Statistics, 33(3), 366-380.

Vahid, F., \& Engle, R. F. (1993). Common Trends and Common Cycles. Journal of Applied Econometrics, 8(4), 341-360.

Zadrozny, P. A. (2016). Extended Yule-Walker Identification of VARMA Models With Single-or Mixed-Frequency Data. Journal of Econometrics, 193(2), 438-446. 